Provided for non-commercial research and education use. Not for reproduction, distribution or commercial use.

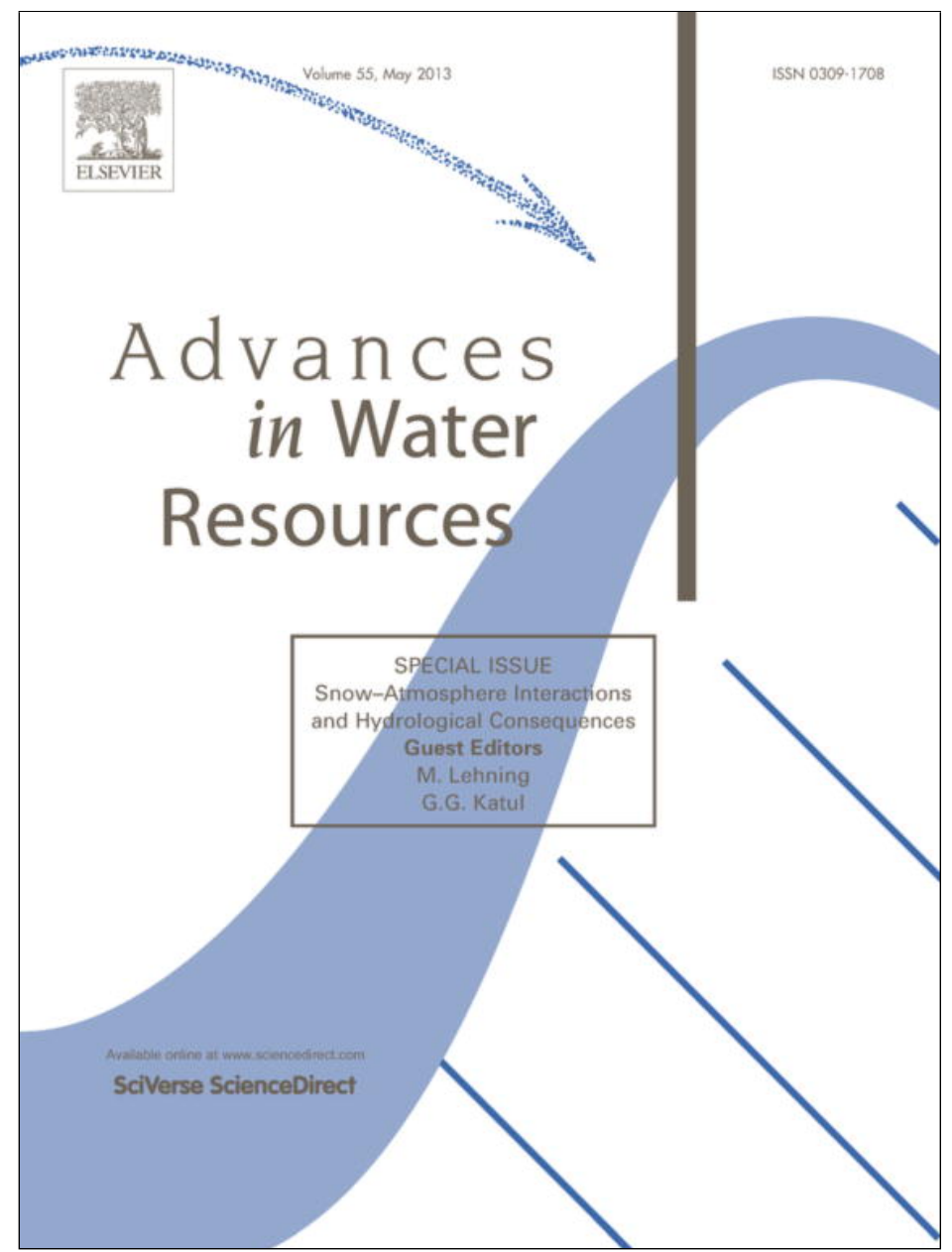

This article appeared in a journal published by Elsevier. The attached copy is furnished to the author for internal non-commercial research and education use, including for instruction at the authors institution and sharing with colleagues.

Other uses, including reproduction and distribution, or selling or licensing copies, or posting to personal, institutional or third party websites are prohibited.

In most cases authors are permitted to post their version of the article (e.g. in Word or Tex form) to their personal website or institutional repository. Authors requiring further information regarding Elsevier's archiving and manuscript policies are encouraged to visit:

http://www.elsevier.com/authorsrights 


\title{
Improving the degree-day method for sub-daily melt simulations with physically-based diurnal variations
}

\author{
Cara Tobin $^{\mathrm{a}, *}$, Bettina Schaefli ${ }^{\text {a }}$, Ludovico Nicótina ${ }^{\mathrm{b}}$, Silvia Simoni ${ }^{\mathrm{c}, \mathrm{d}}$, Guillermo Barrenetxea ${ }^{\mathrm{f}}$, \\ Russell Smith ${ }^{\mathrm{g}}$, Marc Parlange ${ }^{\mathrm{c}}$, Andrea Rinaldo ${ }^{\mathrm{a}, \mathrm{e}}$
}

${ }^{a}$ Laboratory of Ecohydrology (ECHO), School of Architecture, Civil and Environmental Engineering (ENAC), Ecole Polytechnique Fédérale de Lausanne (EPFL), Lausanne, Switzerland ${ }^{\mathrm{b}}$ Risk Management Solutions Ltd., EC3R 8NB London, United Kingdom

${ }^{\mathrm{c}}$ Environmental Fluid Mechanics Laboratory (EFLUM), School of Architecture, Civil and Environmental Engineering (ENAC), Ecole Polytechnique Fédérale de Lausanne (EPFL), Lausanne, Switzerland

${ }^{\mathrm{d}}$ Mountain-eering Srl, Bolzano, Italy

e Dipartimento IMAGE, Universitá di Padova, Italy

${ }^{\mathrm{f}}$ Audiovisual Communications Laboratory (LCAV), School of Computer and Communication Sciences (IC), Ecole Polytechnique Fédérale de Lausanne (EPFL), Lausanne, Switzerland

${ }^{\mathrm{g}}$ WaterSmith Research, Kelowna, Canada

\section{A R T I C L E I N F O}

\section{Article history:}

Available online 23 September 2012

\section{Keywords:}

Snowmelt comparison

Temperature index methods

Spatially-explicit hydrological modeling

Wireless meteorological network

\begin{abstract}
A B S T R A C T
This paper proposes a new extension of the classical degree-day snowmelt model applicable to hourly simulations for regions with limited data and adaptable to a broad range of spatially-explicit hydrological models. The snowmelt schemes have been tested with a point measurement dataset at the Cotton Creek Experimental Watershed (CCEW) in British Columbia, Canada and with a detailed dataset available from the Dranse de Ferret catchment, an extensively monitored catchment in the Swiss Alps. The snowmelt model performance is quantified with the use of a spatially-explicit model of the hydrologic response. Comparative analyses are presented with the widely-known, grid-based method proposed by Hock which combines a local, temperature-index approach with potential radiation. The results suggest that a simple diurnal cycle of the degree-day melt parameter based on minimum and maximum temperatures is competitive with the Hock approach for sub-daily melt simulations. Advantages of the new extension of the classical degree-day method over other temperature-index methods include its use of physically-based, diurnal variations and its ability to be adapted to data-constrained hydrological models which are lumped in some nature.
\end{abstract}

(c) 2012 Elsevier Ltd. All rights reserved.

\section{Introduction}

Hydrologic prediction in Alpine regions critically depends on the simulation of snowmelt processes, e.g. to predict discharge regimes for hydropower production [62] or for real-time flood forecasts where runoff volumes depend on total rainfall and meltwater input [70]. A range of snowmelt methods of different complexity and data requirements exists. If seasonal streamflow distributions are sought, however, the complexity of any snowmelt simulation method should be in balance with that of the hydrologic response model for which it is being developed.

The most detailed methods include distributed snowmelt and hydrological models which use a full energy balance approach [40]. Such approaches are demanding in terms of data collection and computations. For many real-world applications in sparsely gauged catchments [61], however, detailed methods are not feasi-

\footnotetext{
* Corresponding author.

E-mail address: ctobin@stanfordalumni.org (C. Tobin).
}

ble and much simpler methods are required. A popular simple snowmelt simulation method for catchment-scale hydrological models is the temperature-index approach relating snowmelt rates directly to air temperature via a so-called degree-day factor $[19,14,63,6]$.

Whether full energy balance models outperform simpler temperature-index approaches in terms of simulating catchment-scale discharge or melt is currently an ongoing debate $[36,74,65,13]$. Based on the work of Ohmura [48], it is commonly accepted that the good performance of heuristic temperature-based methods can be explained based on physical reasons; temperature is a physical variable controlling the rates of longwave radiation and sensible heat flux and is highly correlated to the three most important energy sources which determine snowmelt: incoming longwave radiation, absorbed global radiation (shortwave) and sensible heat flux. However, using solely temperature as a proxy for snowmelt neglects vapor pressure, wind, and reflected radiation, quantities known to influence the energy balance and snowmelt processes $[36,49,11]$. 
Accordingly, basic temperature-index models cannot account for the high natural variability of melt rates [5], a problem which is exacerbated if such melt models are combined with simplified, lumped rainfall-runoff schemes that further smooth the hydrologic response or if they are used for small time steps which need to capture diurnal cycles (e.g., hourly time steps are typically required for hydrologic applications).

In order to increase the physical basis and to emulate simplified energy balance models, there are many research efforts in progress to include more physical information in temperature-index models (i.e. extended approaches). The most straightforward extension is the incorporation of global radiation measurements which distribute melt in space according to local factors of aspect and account for varying solar position $[9,10,36,12,32,24,13,28]$. Further research has tried to include the evolution of snow density and snow cover albedo over the melt season $[4,50,49,11,41,20]$. This seasonality can also be emulated with time-varying snowmelt factors, e.g. as a function of snow density [37].

The most widely used extended temperature-index approach was proposed by Hock [23], accounting for incoming potential radiation of differently exposed (aspect, slope), regularly spaced grid cells $[25,31,34,42,33]$. This approach has been shown to give good results at the catchment scale, in particular for sub-daily and spatially distributed simulations of snowmelt $[23,29,35]$.

This approach, which we call hereafter the "Hock method", has, however, several shortcomings: First of all, studies have highlighted that it is oversensitive to temperature variations [49,71]. Secondly, while being almost universally applicable given the wide-spread availability of digital terrain models (DEM), it does not account for actual incoming radiation, i.e. actual weather conditions. It might be argued that the method mimics diurnal melt cycles disconnected from real variations of the melt-temperature relation. Finally, the melt method is solved on a finely discretized scale to account for the spatial heterogeneity of terrain slopes and aspects; the resulting snowmelt at a fine grid-scale is often averaged over some coarser areal units to provide melt input to (semi-) lumped hydrological models that are set up for practical applications [71]. This "upscaling" smoothes the simulated spatial variability of snowmelt and the net effect of including high spatial details in the snowmelt routine on the simulated catchment discharge is not trivial to quantify.

This work proposes a new, time-variable melt method based on the classical degree-day method to overcome these shortcomings. The new method uses observed or interpolated daily temperature extremes to impose a diurnal cycle on the melt rates at the scale of the precipitation-runoff transformation model (i.e. each subcatchment has its specific melt rates). To assess the performance of this new, time-variable degree-day method and to compare it to the classical degree-day method and the Hock method, analyses on three scales are conducted as listed below.

1. Initially, the classical degree-day (CD) and time-variable degree-day (TD) methods are compared on a point scale by comparing observed snowmelt lysimeter outflow and simulated snowpack outflow. This analysis provides a general idea of the performance of the TD method at a point location.

2. The CD, TD and Hock methods are subsequently tested with a distributed point dataset to compare the melt model performance in terms of melt simulated over a certain melt period. The purpose of the distributed point analysis is twofold: (a) to understand how well the widely-used Hock method 'mimics' the effect of real (and not potential) radiation on snowmelt and (b) to test whether the models show a performance difference depending on the dominant aspect of the locations of temperature observations (which should help to elucidate the question whether the relationship between snowmelt and temperature is stronger for certain aspects).
3. Finally, the methods are compared on a catchment-scale analysis with a so-called spatially-explicit model of the hydrologic response. This analysis assesses the performances of the melt models in terms of catchment-scale hydrology, which is a commonly accepted method to evaluate the performance of snowmelt routines (see namely $[10,23,24]$ ).

The ultimate goal of the steps of this approach is to demonstrate the performance of the TD method, which has been developed to capture sub-daily melt fluctuations for a range of data-constrained, minimalist hydrological models which are typically used for realworld applications.

A review of the datasets is provided in Section 2 of this paper while the modeling approaches and experimental set-up are detailed in Section 3 and 4 respectively. Results, in Section 5, compare the temperature-index approaches in terms of whether the methods properly reflect actual melt conditions. This paper concludes with a summary of the findings in Section 6.

\section{Data and study catchment}

\subsection{Point scale analysis}

The Cotton Creek Experimental Watershed (CCEW) catchment is a study site used to examine the impact of forest harvesting on peak flows in montane catchments. As spring snowmelt dominates the hydrology, frequent, distributed snow measurements have been collected in order to analyze the spatial and temporal variability of melt. Data for the point scale analysis were utilized from two sites in the CCEW. Hourly precipitation is from the Cotton Upper climate station (CIU, $1780 \mathrm{~m}$ a.s.l), and hourly air temperature and snowmelt lysimeter outflow are from a hillslope monitoring site (Site 6003, $1652 \mathrm{~m}$ a.s.l.) located approximately $1500 \mathrm{~m}$ north of CIU $[66,28]$. Periodic snow depth measurements from the spring snowmelt seasons of 2007 and 2008 are used to calibrate and validate the melt model's snow height predictions, respectively. The hourly snowmelt lysimeter data permit testing of the sub-daily dynamics for the CD and TD melt methods. Further details of the dataset are available in Smith [66] and in Jost et al. [28].

\subsection{Distributed point and catchment analysis}

Data for the distributed and catchment-scale studies were obtained from a high resolution, wireless sensor network installed in June 2009 in the Dranse de Ferret catchment located in the Valais region in the central part of the Alps, at the border between Switzerland and Italy (Fig. 1). Data were collected at 1 min intervals between June and October 2009 and are accessible in real time on the internet (www.climaps.com). Prior to June, snow accumulations and the risk of avalanche made the transport and installation of the meteorological stations impossible. For the 2009 field campaign, the wireless sensor network consisted of 12 "Sensorscope" stations. Two of the 10 stations were located on the glacier (see Fig. 1) which collected data between September and mid-October (due to installation challenges). For this analysis, the stations located on the glacier were not utilized due to the short time span of the data and since the data could not be obtained during the melting season (notably April through the beginning of July for this region).

The "Sensorscope" technology [27] measures various meteorological data, including: air temperature at $1.5 \mathrm{~m}$ above ground, precipitation, incoming shortwave radiation, skin temperature, humidity, wind speed and wind direction as well as soil moisture, soil temperature and suction. Profiles of the temperature and radi- 

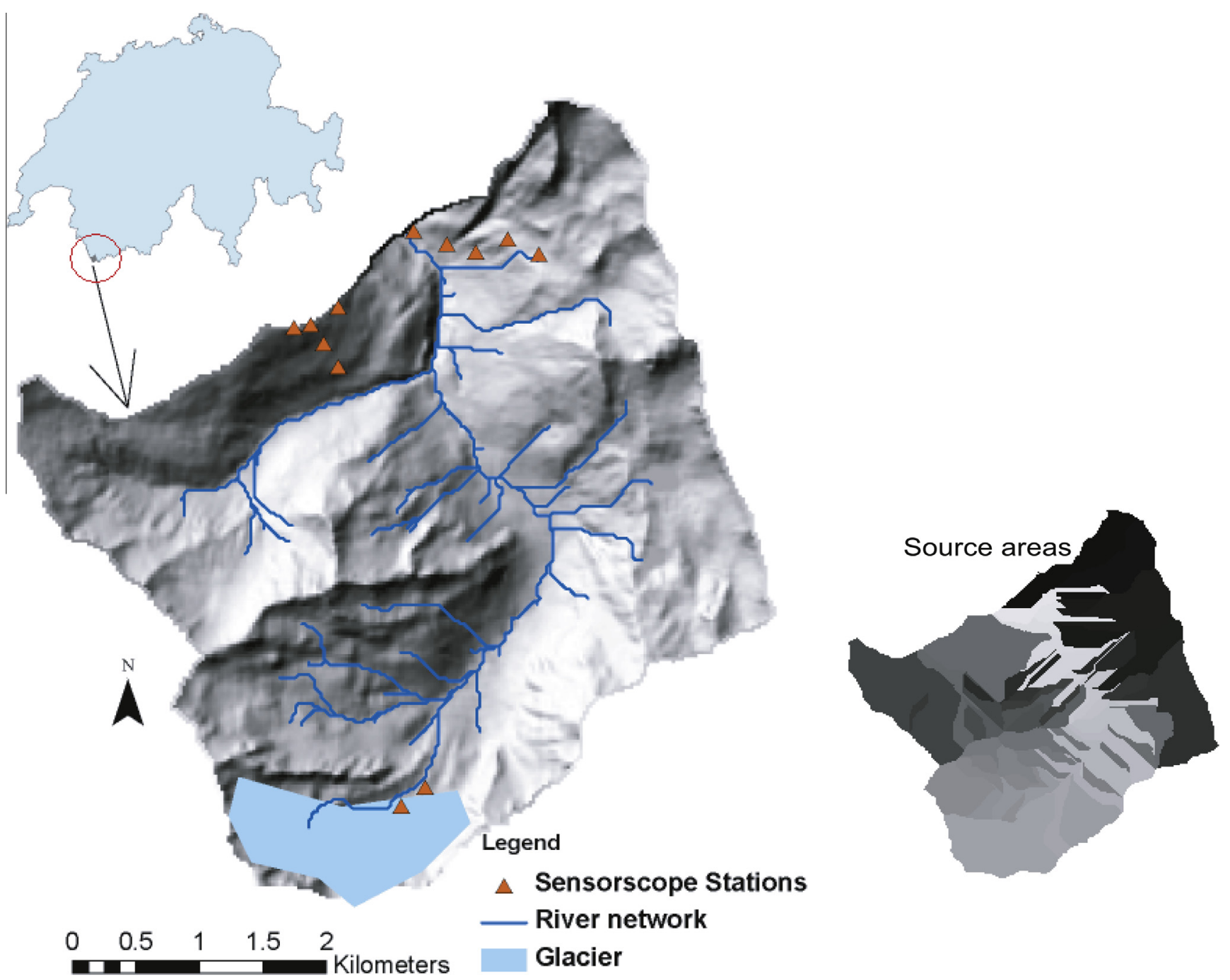

Fig. 1. Map of the Dranse de Ferret catchment indicating locations of Sensorscope meteorological stations, the glacier, and the river network generated based on the digital elevation model ( $25 \mathrm{~m}$ resolution) indicated in gray shades. Top inset: location of this catchment within Switzerland; bottom inset: location of source areas.

ation measured at one station can be seen in Fig. 2. For further technical details on measuring devices used, refer to the work of Nadeau et al. [44] and Simoni et al. [64].

It should be noted that temperature measurements from passively ventilated sensors (such as those used in this wireless sensor network field campaign) have an inherent bias due to heating of the radiation shield (e.g. [26]). However, in this study the temperatures could not be corrected as proposed in Huwald et al. [26] due to a lack of reflected shortwave radiation measurements and the wide range of albedo observed at the different stations.

For the distributed point data analysis, temperature, precipitation and radiation data are used from the 10 non-glacier stations located in two groups to test the performances of the CD, TD and Hock melt methods. Each group is composed of five stations and located on either the southeast or southwest face of the region. The stations are located at elevations ranging between 1780 and $2300 \mathrm{~m}$ on the southwest-facing slope and between 2160 and $2430 \mathrm{~m}$ on the southeast-facing slope. Compared to previous research conducted at the site scale [36,29] with distributed measurements $[12,49,74,2]$, the locations of the meteorological stations offer a unique opportunity to compare the melt method performances relative to temperature measurements from differing aspects.

The mean positioning of the groups is different where the southeast facing group is more south-facing than the southwest facing group [64]. In effect, incoming shortwave radiation values were recorded to be approximately $8 \mathrm{~W} \mathrm{~m}^{-2}$ higher for the southeast facing group throughout the 5 month field experiment and, the groups, separated by approximately $1 \mathrm{~km}$, do not show well correlated temperature lapse rates. For the southeast facing stations, the mean hourly lapse rate over the experimental period was $-0.0075^{\circ} \mathrm{C} \mathrm{m}^{-1}$ whereas the mean hourly lapse rate for the southwest facing stations was $-0.0054^{\circ} \mathrm{C} \mathrm{m}^{-1}$. Within such an Alpine environment, the spatial distribution of surface temperatures is strongly influenced by the complex topography and related effects on the energy balance (e.g., local wind systems, differences in expositions and shading). These effects cannot be captured by a simple temperature lapse rate. For the purpose of this study, it is nevertheless assumed that the contrasting lapse rates between the two groups of measurement stations reflect differences in the radiation balance that are likely to influence snowmelt rates.

For the catchment-scale analysis, the same meteorological variables from the 10 stations are used to test the performances of the three melt methods, however, these data were spatially distributed throughout the catchment using interpolation (see Experimental Set-up Section 4). The Dranse de Ferret catchment site has a total surface area of $21 \mathrm{~km}^{2}$. The altitude ranges between $1775 \mathrm{~m}$ and $3206 \mathrm{~m}$ a.s.l. and the catchment is drained by the Dranse de Ferret river. The Dranse de Ferret catchment has steep slopes and is sur- 
(a)
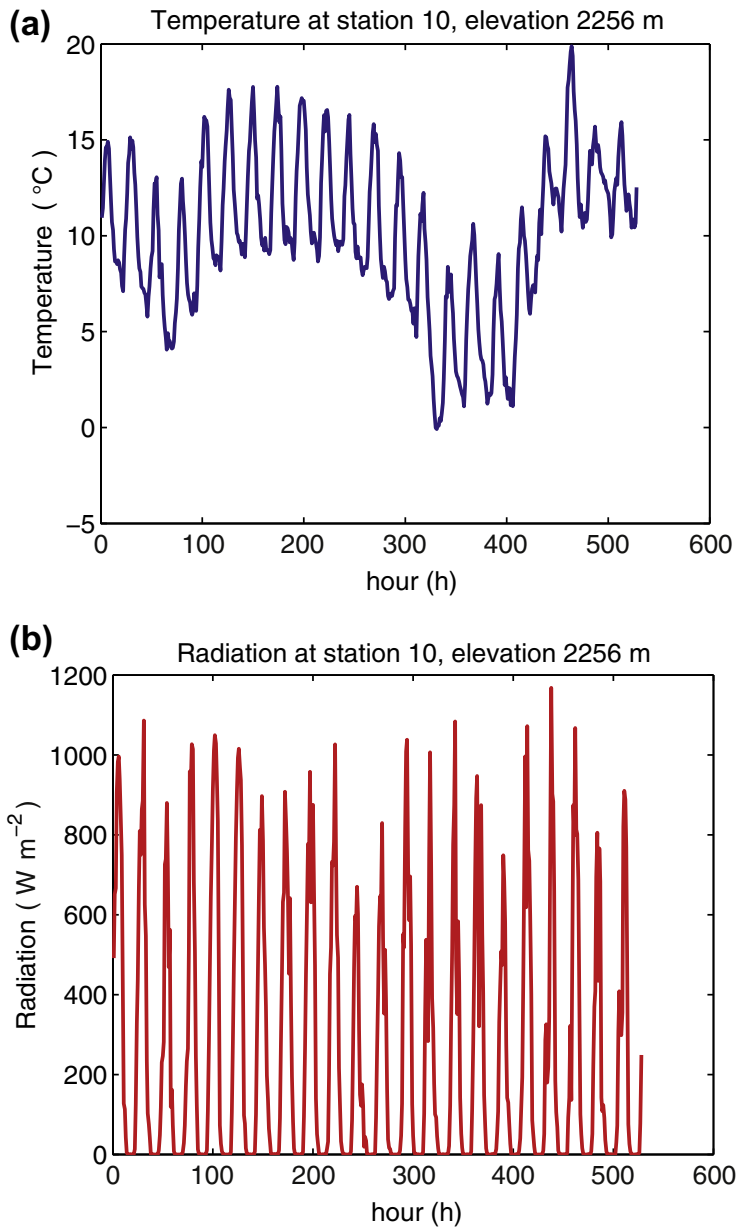

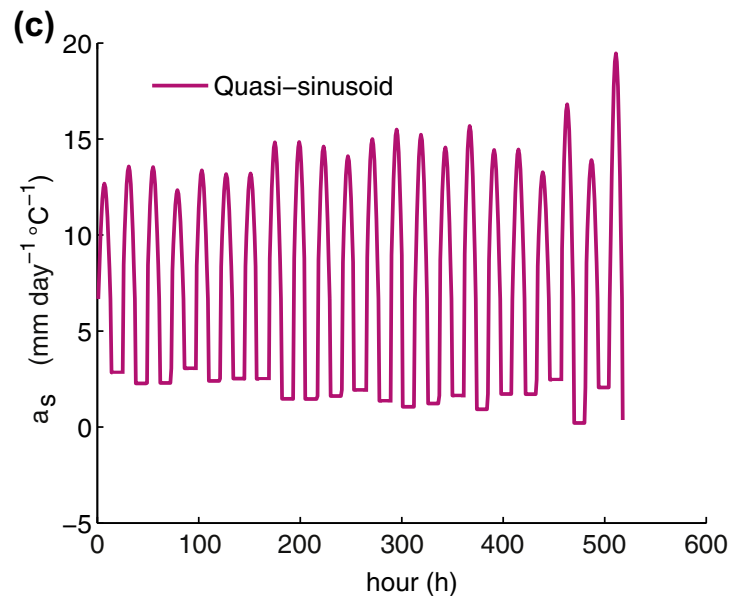

Fig. 2. (a) Measured temperature and (b) measured radiation at station 10 (elevation $2256 \mathrm{~m}$ ) during the simulation period used in the distributed point and catchment-scale analyses. (c) $a_{s}$ as a function of time, illustrating the quasi-sinusoidal function of Eq. (2).

rounded by high mountains (e.g. the nearby Grand St. Bernard pass, $2500 \mathrm{~m}$ a.s.l.). Approximately $5 \%$ of the catchment area is covered by glacier. Due to the high mountainous location of the catchment, the climatic regime is particular; annual rainfall in this region can locally exceed $2 \mathrm{~m} \mathrm{y}^{-1}$ and discharge peaks in the spring due to snowmelt.

Water level data are available from a flow meter constructed at the outlet of the catchment. The stage-discharge curve was obtained with the salt dilution method [64]. The resulting discharge profile can be seen in Fig. 3. Analysis of the discharge from this dataset was originally conducted by [64], where the contributions of glacier melt, snowmelt, rainfall-runoff and baseflow to the discharge time series were detailed. Once the baseflow is subtracted, snowmelt composes approximately $85 \%$ of the remaining discharge volume, whereas glacier melt comprises less than $10 \%$. Due to its small impact on the discharge signal, this study has neglected glacier melt in the calibration of the hydrological model.

\section{Modeling approaches}

Simulation of snowmelt-induced hydrologic processes requires a suite of modeling steps: (i) characterization of solid and liquid water input to the system (rainfall, snowfall), (ii) modeling of the snowpack evolution, its solid and liquid water content (resulting from rainfall, snowmelt and refreezing) and water outflow from the snowpack, in addition to (iii) transformation of the so-called equivalent precipitation (total water outflow from the snowpack plus rainfall on snow-free ground) to river discharge. In the context of this paper, the focus is on the newly proposed snowmelt algorithm, the TD method; for all other modeling steps, only the essential details are presented.

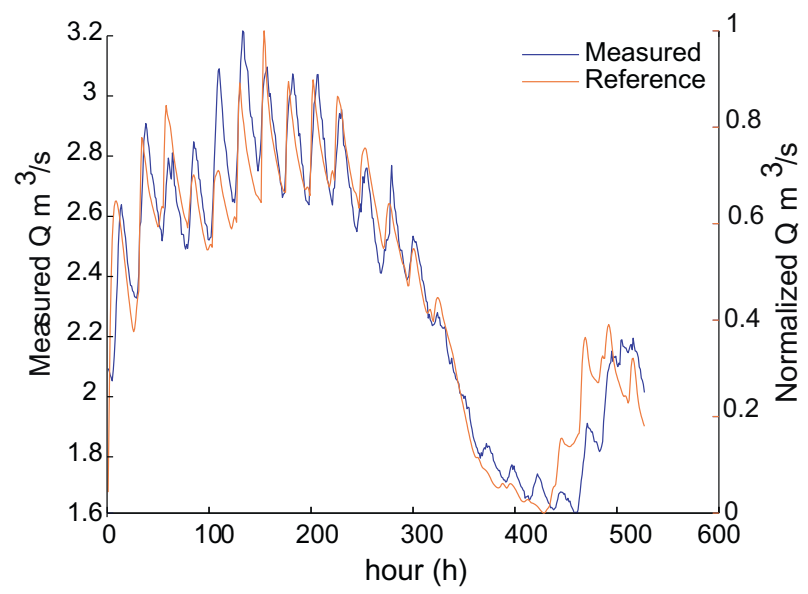

Fig. 3. Catchment-scale analysis: (left) measured discharge $Q\left(\mathrm{~m}^{3} \mathrm{~s}^{-1}\right)$, (right) normalized measured and reference discharge $Q\left(\mathrm{~m}^{3} \mathrm{~s}^{-1}\right)$. 


\subsection{Aggregation state of precipitation}

The partitioning of precipitation into snow- and rainfall is obtained with a linear transition between $0{ }^{\circ} \mathrm{C}$ and $2{ }^{\circ} \mathrm{C}$, where below $0{ }^{\circ} \mathrm{C}$, all the precipitation is considered to fall as snow, for temperatures above $2{ }^{\circ} \mathrm{C}$, only rainfall occurs and between the two thresholds a mixture of rainfall and snowfall occurs (see, e.g., [74,22]). The temperature interval has been fixed based on observations from the Swiss Alps [60].

\subsection{Snowmelt and refreezing}

Three snowmelt methods, based on the temperature-index concept, are analyzed in this study: (1) the classical degree-day method with a constant degree-day factor (the CD method), (2) the well-known method proposed by Hock [23], called the Hock method hereafter, and (3) the new approach with a degree-day factor that varies within the day (the TD method).

The constant degree-day method, the simplest temperatureindex snowmelt method, is based on the assumption that melt rates depend solely on air temperature [53]. According to this formulation, the rate of snowmelt, at location $\mathbf{x}$ and at time $t, M$ $(\mathbf{x}, t)\left(\mathrm{mm} \mathrm{h}^{-1}\right)$ is given by:

$$
M(\mathbf{x}, t)= \begin{cases}\frac{a_{c}\left(T(\mathbf{x}, t)-T_{0}\right)}{n} & T(\mathbf{x}, t)>T_{0} \\ 0 & T(\mathbf{x}, t) \leqslant T_{0}\end{cases}
$$

where $T(\mathbf{x}, t)$ is the air temperature at a location $\mathbf{x}$ at time $t(\mathrm{~h}), T_{0}$ is the constant threshold temperature above which melt occurs (here assumed to be $\left.0{ }^{\circ} \mathrm{C}\right), a_{c}\left(\mathrm{~mm}\right.$ day ${ }^{-1}{ }^{\circ} \mathrm{C}^{-1}$ ) is the constant degree-day factor and $1 / n$ is the time-step conversion factor with $n=24(\mathrm{~h} / \mathrm{d})$. $a_{c}$ represents the rate of snowmelt corresponding to one degree of positive temperature during one day.

In the Hock method, the above basic melt equation is modified to account for the local estimate of potential (clear-sky) incoming solar radiation $I_{\text {pot }}\left(\mathrm{W} \mathrm{m}^{-2}\right)$ in the form:

$$
M(\mathbf{x}, t)= \begin{cases}{\left[\frac{1}{n} a_{i}+\rho_{i} I_{p o t}(\mathbf{x}, t)\right]\left(T(\mathbf{x}, t)-T_{0}\right)} & T(\mathbf{x}, t)>T_{0} \\ 0 & T(\mathbf{x}, t) \leqslant T_{0}\end{cases}
$$

where $a_{i}$ is the melt factor ( $\mathrm{mm}$ day $^{-1}{ }^{\circ} \mathrm{C}^{-1}$ ) and $\rho_{i}$ is a radiation coefficient for snow $\left(\mathrm{m}^{2} \mathrm{~W}^{-1} \mathrm{~mm} \mathrm{~h}^{-1}{ }^{\circ} \mathrm{C}^{-1}\right)$. Clear-sky incoming potential solar radiation $\left(I_{p o t}\right)$ is simply inferred from geographic location (latitude) and topography (shading, local slope, aspect and elevation). According to Hock [23], the empirical snowmelt model parameter, $\rho_{i}$, has been fixed in this study to $0.6 \times 10^{-3}\left(\mathrm{~m}^{2} \mathrm{~W}^{-1} \mathrm{~mm} \mathrm{~h}^{-1}{ }^{\circ} \mathrm{C}^{-1}\right)$. Note that $a_{i}$ is usually called melt factor rather than degree-day factor to avoid confusion between the methods. In the remainder of this paper, the generic term degree-factor will be used for both $a_{c}$ and $a_{i}$.

A modified version of the $C D$ method is herein proposed. In this case the degree-day factor is allowed to vary throughout the day, to account for the actual distribution of snowmelt rates in time, which peaks at the hours of maximum incident radiation and falls to a minimum during the night. We, thus, assume that the snowmelt rate follows the typically sinusoidal variation of radiation during the day and that it is constant during the night, i.e. we impose a quasi-sinusoidal function (Fig. 2c) of time-variability on the degree-day factor. The amplitude of the degree-day factor's daily cycle variability cannot be directly related to actual radiation because this variable is rarely measured. We, therefore, assume that the daily temperature amplitude (difference between daily maximum and daily minimum temperature) is a good proxy of the amplitude of the daily cycle of incoming radiation and that it can efficiently discriminate between days when there is a strong within-day variability of radiation (and thus of snowmelt rates) and days with a low variability.
This new time-variable degree-day factor $a_{s}$, which replaces the constant $a_{c}$ in Eq. (1) can be written as:

$a_{s}\left(t_{d}\right)= \begin{cases}a_{c}+\beta \Delta_{T}(d) \sin \left(\pi \frac{t_{d}-t_{0}}{t_{1}-t_{0}}\right) & t_{0} \leqslant t_{d}<t_{1} \\ a_{c}-\beta \Delta_{T} Z & \text { otherwise }\end{cases}$

where $t_{d}(\mathrm{~h})$ is the hour of the day $d, t_{0}(\mathrm{~h})$ is the start time of daylight and $t_{1}(\mathrm{~h})$ is the end of daylight on day $d . a_{c}\left(\mathrm{~mm} \mathrm{day}^{-1}{ }^{\circ} \mathrm{C}^{-1}\right)$ is the constant degree-day factor, $\Delta_{T}(d)\left({ }^{\circ} \mathrm{C}\right)$ is the difference between the maximum and the minimum daily temperature on day $d$ and $\beta$ ( $\mathrm{mm}$ day $^{-1}{ }^{\circ} \mathrm{C}^{-2}$ ) is a factor to convert the temperature amplitude into a degree-day factor amplitude which has to be calibrated (considering the constraint that $a_{s}$ has to be positive for positive temperatures). $Z(-)$ is a factor to ensure that the daily mean value of $a_{s}$ equals $a_{c}$, i.e. that the integral of the sinusoidal function during the day time equals the integral of the constant value during the night, i.e.

$Z=\frac{\int_{t_{0}}^{t_{1}} \sin \left(\pi \frac{t_{d}-t_{0}}{t_{1}-t_{0}}\right) d t_{d}}{l_{n}}=2 \frac{t_{1}-t_{0}}{\pi l_{n}}$,

where $l_{n}=24-t_{1}+t_{0}(\mathrm{~h})$ is the length of the night. Note that $t_{0}$ and $t_{1}$ could also be allowed to be a function of $d$ rather than constant.

The snowmelt method resulting from applying Eq. (3) with $a_{s}$ is called the time-variable degree-day method (TD). The resulting degree-day factor shows sub-daily fluctuations around a constant mean value; the amplitude of these fluctuations is proportional to the daily temperature amplitude, which accounts for cloudy or rainy days when incoming radiation decreases (Fig. $4 \mathrm{a}$ and b). Note that there was a previous attempt to account for the within-day variability of temperature for snowmelt computation by Dunn and Colohan [14], who considered only the fraction of the day when the temperature exceeded a critical threshold for melt rather than the mean daily temperature for daily melt computations.

For hourly snowmelt simulations, refreezing during periods when the temperature drops below the critical threshold for melt has to be considered. For all melt methods analyzed, refreezing is calculated analog to melting:

$F(\mathbf{x}, t)= \begin{cases}\frac{a_{f}(t)\left(T(\mathbf{x}, t)-T_{0}\right)}{n} & T(\mathbf{x}, t) \leqslant T_{0} \\ 0 & T(\mathbf{x}, t)>T_{0}\end{cases}$

where $a_{f}\left(\mathrm{~mm} \mathrm{day}^{-1}{ }^{\circ} \mathrm{C}^{-1}\right)$ is the refreezing factor. This refreezing factor is often linearly related to the degree-day factor [1] through a multiplicative factor $a_{r}(-)$ to account for the fact that refreezing with negative temperatures is usually assumed to be lower than the corresponding melt rates with positive temperatures (but e.g. [3] assumes $\left.a_{r}=1\right)$. Accordingly, $a_{f, x}=a_{r} a_{x}$ where $x=c, i, s$ stands for one of the three degree-day factors. The calibrated factor $a_{f}$ is used in place of the degree-day factors when the temperatures fall below or equal to the threshold temperature $T_{0}$. The melt equations defined by $M(\mathbf{x}, t)$ are replaced by the freezing equation $F(\mathbf{x}, t)$ in this case.

Melt generated by the TD method and the Hock method are distributed in space and time. (The CD method is assumed constant in time and space.) The Hock method is defined on a pixel basis due to its use of solar positioning data and a digital terrain model. Melt per pixel from the Hock method is summed on a subcatchment basis for use in the hydrological model (Section 3.3). The TD method is distributed in time and space with the time-varying quasi-sinusoidal function defined by the temperature extremes in each subcatchment, thereby remaining constant in each subcatchment.

\subsubsection{Snowpack evolution}

The evolution of the solid and the liquid water content (in terms of snow water equivalent) of the snowpack is simulated separately. The solid store has as input snowfall and as output, snowmelt; the 


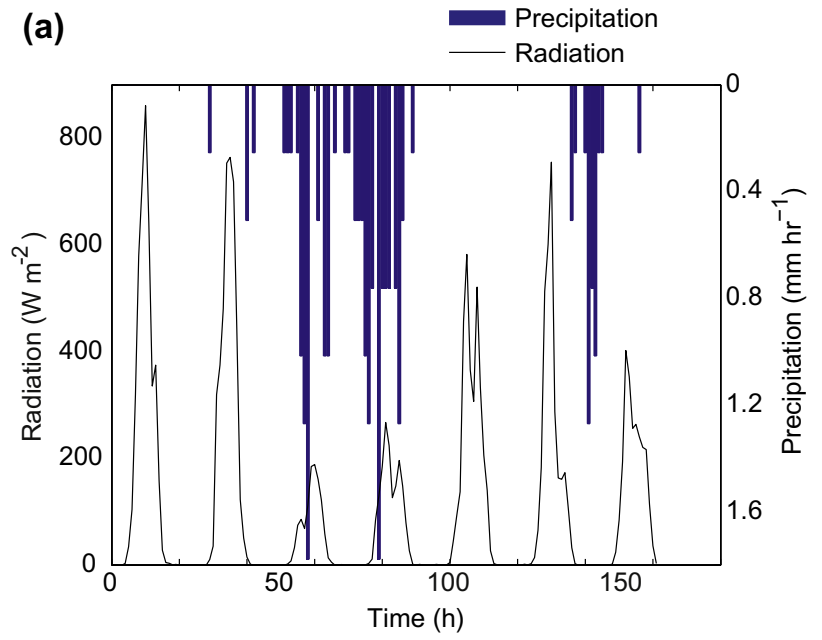

(b)

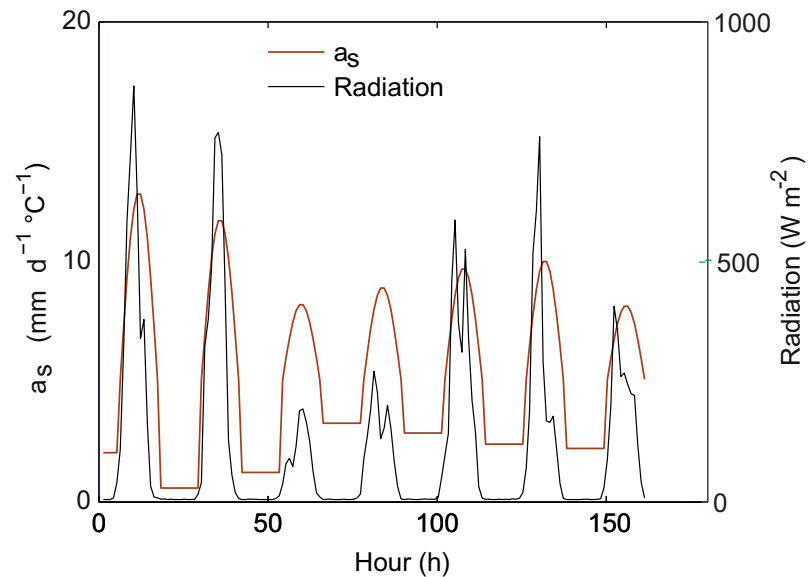

Fig. 4. (a) The measured radiation and precipitation time series averaged over all Sensorscope stations during a rain event and (b) the corresponding time series of the timevariable degree-day factor $a_{s}$.

liquid store has as inputs, snowmelt and rainfall, and as outputs, snowpack outflow and refreezing [see 22]; the routine is very similar to the snowmelt routine of the well-known HBV model [3].

At every time step, the ratio of the liquid to solid water store in the snowpack (the snowpack's relative liquid water content) is computed. Water outflow of the liquid store (called snowpack outflow) only occurs if this relative liquid water content is above a critical retention capacity $\theta_{r}$, which is either calibrated or fixed to a value of a few percent.

\subsection{Spatially-explicit hydrological model}

For the catchment-scale analysis, a spatially-explicit hydrological model is used to integrate the melt methods. With this model, the snowpack outflow together with rainfall on snow-free catchment parts (the so-called equivalent precipitation) is transformed into river discharge, based on the formulation of transport by travel time distributions $[59,18,58]$. The catchment is partitioned into a series of source areas with the aid of a digital terrain model (DEM) following the method presented in [68]. This concept of source areas is comparable to the concept of hydrological response units, HRUs (e.g. [74]). Elevation, aspect and slope are the criteria for source area delineation. The areas are defined to preserve relatively homogeneous melting conditions per area (similar to the original work of Cazorzi and DallaFontana [12].

In each source area, runoff partitioning of the equivalent precipitation is performed via a minimalist water balance approach that describes the dynamics of soil moisture at the source catchmentscale $[38,56,57]$ :

$\eta Z_{r} \frac{d s(t)}{d t}=F_{I}(t)-E[s(t)]-L[s(t)]$

where $\eta$ represents soil porosity $(-), Z_{\mathrm{r}}$ is the depth of the active soil layer during water redistribution processes $(\mathrm{mm})$ and $F_{I}$ is the infiltration flux $\left(\mathrm{m} \mathrm{s}^{-1}\right) . E$ and $L$ represent the rate of evapotranspiration and the rate of mobilized water (outflux from the soil moisture store) respectively and are functions of the catchment averaged soil moisture filling. $E$ is assumed to be null for $s$ below the wilting point and it equals the potential evapotranspiration if $s$ equals $65 \%$ of the field capacity. Potential evapotranspiration is evaluated with the Priestley-Taylor method [43,51]. $L$ is modeled as a linear function of the soil moisture. Resulting subsurface flow as well as surface flow from non-infiltrated water is computed using a classical linear reservoir approach (for details see [47]).

Soil depth in the model is considered homogeneous for the source area. For the case study region, preliminary results showed that including spatially variable soil depths in the model does not improve the hydrological model performance; this has several reasons: there is a limited range of soil depths in this region (generally between 0 for exposed rocks and about $20-30 \mathrm{~cm}$ for steep slopes), other factors of spatial variability dominate over soil depth heterogeneity (e.g., steep, complex topography) and the fact that, as in any conceptual model, the different model parameters can compensate for each other during model calibration [47]. In general, this assumption would not fit an experiment with more variable soil depths.

The travel time distribution $[18,55,58,8,54,7]$ at the outlet is obtained as (see [46] for more detail):

$f(t)=\sum_{\gamma \in \Gamma} p(\gamma, t) f_{\gamma}(t)$

where $\Gamma$ is the set of all possible flow paths (surface and subsurface flow) from all source areas to the catchment outlet (reflecting the spatial structure of the catchment), $f_{\gamma}(t)$ is the probability density function of travel times in a given flow path $\gamma$ (composed of hillslopes and channel states) and $p_{\gamma}$ is the probability that a water input to the catchment follows a given flow path $\gamma$. For each time step and each flow path $\gamma$, this probability is obtained from the ratio of water input (surface or subsurface) to the given source area divided by the total water input to the entire catchment.

Total surface and subsurface flow rates at the catchment outlet are obtained by time convolution of the corresponding water fluxes with the appropriate residence time distributions for all paths $\gamma$ :

$Q(t)=\sum_{\gamma \in \Gamma} \int_{0}^{t} J(\gamma, \tau) f_{\gamma}(t-\tau) d \tau$

where $J(\gamma, t)$ is the net input to the path $\gamma$ accounting explicitly for the probability that water enters this path.

In summary, in such a spatially-explicit model, the hydrologic response of a water input event (rainfall or water outflow from the snowpack) is determined by the set of flow paths that are activated by the spatial input pattern and by the volume of water traveling through the individual paths relative to the total water input to the catchment. 


\section{Experimental set-up}

\subsection{Point-scale analysis}

The performance of the proposed TD method is compared against the CD method for the point scale dataset from the CCEW $[66,28]$. Both models are calibrated on the spring melt seasons so that the simulated snowpack outflow reproduces as closely as possible the observed snowmelt lysimeter outflow (the calibration criterion is the sum-of-squared-errors, SSE). The TD method has 4 parameters to calibrate $\left(a_{s}, \beta, a_{r}, \theta_{c r}\right)$ while the CD method has three parameters to calibrate $\left(a_{c}, a_{r}, \theta_{c r}\right)$. The Hock method will not be compared for the single point analysis because its performance has been demonstrated elsewhere [30,71] and assessing its performance against the new TD method is relevant only for distributed melt simulations (for which the method has been developed). Data from the 2007 hydrological year (November 2007 to October 2008) are used for calibration and data from the 2008 hydrological year are used for validation.

\subsection{Distributed point analysis}

The objective of the distributed point analysis is to investigate how the CD, TD and Hock methods emulate the temporal evolution of available melt energy as a function of hourly temperature and, in the case of the Hock method, as a function of potential radiation and temperature. To assess the behavior of the three methods, the potential melt that would be obtained with each method if the available snow was not limiting, is compared against a reference potential melt series. This reference series is compiled by applying Eq. (2) with $a_{c}$ equal to 3 (mm day ${ }^{-1}{ }^{\circ} \mathrm{C}^{-1}$ ) (which is an average value for such environments, e.g. $[24,49]$ using actual observed radiation at all meteorological stations. The reference melt is then averaged over the stations.

To investigate how the methods perform for different dominant expositions, three different experiments are conducted: Experiment 1 includes all meteorological stations; Experiment 2 includes only the southwest facing stations; and Experiment 3, only the southeast facing stations. Given that the CD, TD and the Hock methods do not consider actual radiation, they do not simulate the same amount of potential melt as the reference simulation if run with the same degree-day factor $\left(3 \mathrm{~mm}\right.$ day ${ }^{-1}{ }^{\circ} \mathrm{C}^{-1}$ ). To obtain a meaningful comparison between the temporal evolution of the different potential melt simulations, the parameters of the $\mathrm{CD}, \mathrm{TD}$ and Hock methods are, thus, calibrated such as to fit as closely as possible the reference simulation (the calibration criterion is the SSE). The CD method has 1 parameter to calibrate $\left(a_{c}\right)$, the TD method has two parameters to calibrate $\left(a_{c}, \beta\right)$ and the Hock method has 1 parameter to calibrate $\left(a_{i}\right)$ (refreezing factors are not applicable due to the high temperatures during the simulation period). The performance of the three melt methods with respect to the reference simulation is evaluated, for each experiment, by comparing the simulated, potential cumulated snowmelt and the reference potential cumulated snowmelt.

\subsection{Catchment-scale analysis}

\subsubsection{Input interpolation}

Spatial interpolation of ground temperature and precipitation measurements is performed through kriging with external drift (KED) (using elevation as auxiliary information) [15]. Previous studies in similar environments have shown the adequacy of regression-based approaches, particularly when high-elevation station data are available to validate data $[16,67,69]$.

Data from the distributed meteorological stations in the two groups (southeast and southwest facing) in the Dranse de Ferret catchment were initially analyzed to detect correlations between temperature and the measured meteorological variables between the groups. Temperature distributions along the vertical direction for each group are controlled solely by elevation gradients in the study period; after removing the elevation effect, all the stations show a mean temperature of $13^{\circ} \mathrm{C}$ at the reference elevation of $1780 \mathrm{~m}$ a.s.l. In effect, the use of elevation as the external drift factor for the KED interpolation seems fully justified.

The radiation is spatially distributed as follows: first, the potential radiation for each DEM grid cell is computed according to the method proposed by Hock [23], which is based on topography (local aspect and slope), solar positioning and geographic location; subsequently, these values are rescaled (at an hourly time step) to match the incoming shortwave radiation measured at the stations (see as an example, Fig. 5). This rescaling procedure takes into account the effect of cloudiness (which decreases the incoming solar radiation) while preserving, however, the spatial structure of the incoming radiation field.

\subsubsection{Initial conditions}

A distributed, initial snow height is determined based on a theoretical snowpack model that gives the annual evolution of the snowpack as a function of the mean annual values of temperature and precipitation and their seasonality and uses a CD snowmelt formulation [73]. Such a simple model distributes the mean snow height for a given time of year as a function of altitude (by simply distributing the mean annual temperature as a function of altitude). In the context of the present study that analyzes simplified snowmelt models, such a rough estimate of how snow height at the start of the modeling period (June) might vary with altitude is assumed to be sufficient. For more comprehensive methods to calculate the gradient of snow depth with elevation see $[17,39]$. The resulting initial snow heights have a minimum of $355 \mathrm{~mm}$ (water equivalent, w.e.) for the lowest source area at a mean altitude of $1890 \mathrm{~m}$ a.s.l. and a maximum of $1.2 \mathrm{~m}$ w.e for the highest source area at a mean altitude of $2745 \mathrm{~m}$ a.s.l.

This initial snowpack height is imposed as a spin-up condition (i.e., for modeling purposes, since measures were not available) in order to simulate an early stage of the melt period when there is still a significant influence of the snowpack contributing to runoff. This approach is used to evaluate the evolution of the snowpack from the beginning of the spring melt season. The initial snow distribution can be assumed to reasonably reflect what could

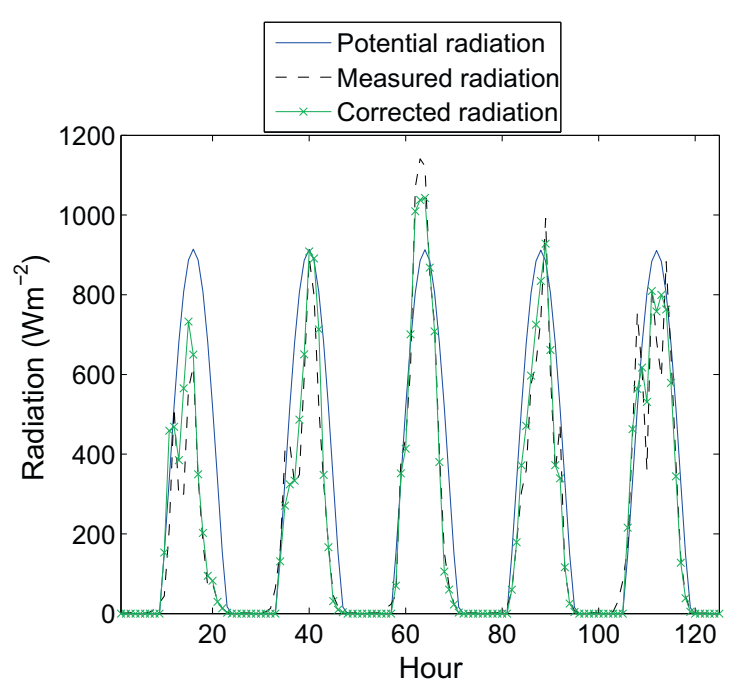

Fig. 5. Mean measured, potential and corrected potential radiation for all 10 nonglacier Sensorscope stations. 
have prevailed earlier in the melt season. This assumption is supported by the findings of Simoni et al. [64], which indicated that the snowmelt stemmed from well-distributed source areas and was a dominant discharge component.

\subsection{Hydrological model set-up}

A total of 89 source areas were identified for the Dranse de Ferret catchment (see inset of Fig. 1). Based on the spatial input fields, each subcatchment was assigned an area-average precipitation time series and a temperature time series. To compare the performance of the melt methods at the catchment-scale, each of the methods were combined with the presented precipitation-runoff model. For each model, the parameters were calibrated such that the simulated discharge follows as closely as possible the reference discharge (see details hereafter).

The reference discharge series for such a calibration is usually observed discharge; for our particular case study, however, we could not use observed discharge directly because spring discharge measurements could not be collected given the risk of avalanche at the experimental catchment. We, thus, generated a reference discharge time series for comparison purposes as follows: The distributed temperatures and precipitation fields, the previously discussed initial snow heights and the distributed, corrected radiation field (see Section 4.3.1) were used as inputs. A parameter set was then selected (within a literature-based prior range, see Table 1) based on its ability to provide reasonable temporal discharge dynamics. The actual observed discharge, while being on a different scale due to lower initial snow heights, was assumed to accurately describe the actual dynamics of the discharge in terms of the coefficient of variation (CV) (hourly discharge variance divided by the hourly mean). Accordingly, the parameter set was chosen such that the $\mathrm{CV}$ of the simulated discharge was as close as possible to the $\mathrm{CV}$ of the observed discharge. The observed discharge $\mathrm{CV}$ is 0.6 and the selected parameter set (see Table 1 ) provides a discharge with a CV of $0.64(-)$.

As shown in Fig. 3, the corresponding reference simulation shows a dynamic very similar to the observed discharge, in terms of daily discharge cycles and a decreasing amplitude towards the end of the melt period (which is typical for high mountainous spring snow discharge [21]). In addition to this reference simulation, we also retained a range of plausible simulations by using Monte Carlo analysis to randomly generate a high number of parameter sets from a uniform distribution spanning the prior parameter range. These additional plausible simulations were selected by retaining the 50 simulations that most closely match

Table 1

Reference hydrological model parameters for Monte Carlo simulation. Note that fo the catchment-scale analysis, all temperatures were always positive (i.e. no refreezing occurred)

\begin{tabular}{lll}
\hline & Value & Unit \\
\hline Soil model & & \\
Porosity, $\eta$ & 0.5 & {$[-]$} \\
Active soil layer depth, $\mathrm{Zr}$ & 300 & $\mathrm{~mm}$ \\
Soil moisture threshold, $s_{*}$ & 0.3 & {$[-]$} \\
Soil moisture at wilting point, $s_{w}$ & 0.05 & {$[-]$} \\
Saturated hydraulic conductivity, $k_{\text {sat }}$ & 20 & $\mathrm{~mm} \mathrm{~h}^{-1}$ \\
Clapp and Hornberger exponent, $c$ & 12.8 & {$[-]$} \\
Initial soil moisture, $s_{o}$ & 0.45 & {$[-]$} \\
Routing model & & \\
Surface discharge residence time & 2 & $\mathrm{~h}$ \\
Subsurface discharge residence time & 20 & $\mathrm{~h}$ \\
Wave celerity & 1 & $\mathrm{~m} \mathrm{~s}^{-1}$ \\
Dispersion coefficient & 1000 & $\mathrm{~m}^{2} \mathrm{~s}^{-1}$ \\
\hline
\end{tabular}

the reference series (based on the SSE). These simulations show a range of possible discharge behaviors around the reference discharge time series (see light red shaded regions around the reference series in Fig. 12).

Once this reference series was established, we calibrated the parameters of the three models (i.e., the combination of $\mathrm{CD}$, TD and Hock melt methods with the precipitation-runoff model) on the reference series using again a Monte Carlo analysis. The resulting discharge profiles were compared to the reference time series. Acceptable simulations were chosen based on two performance indicators: (1) the Nash-Sutcliffe index [45] and (2) the percentage of time steps, $p$ where the simulated discharge falls into the range of plausible reference simulations (see performance indicators in Figs. 12 and 13). Again, rather than retaining a single best parameter set, we retained 50 sets that have a Nash $>0.7$ and $p>80 \%$. This provided a range of behavior for the discharge simulation (see Fig. 12). Through this Monte Carlo calibration procedure, we ensure that the melt methods work with an ensemble of parameter sets which yield reasonable sub-daily discharge variability.

Similar to the distributed point analysis (comparing potential melt), the above procedure is repeated with three numerical experiments to assess the impact of temperature distributions on the ability of the different snowmelt methods to approximate the reference discharge time series. Each of the experiments corresponds to a different scenario of measured temperature inputs: Experiment 1 the whole dataset; Experiment 2 only stations belonging to the southwest facing group; and Experiment 3 only southeast facing stations. The reference series generation procedure and the ensuing model calibration process yield for each experiment, (i) a reference series and its plausible range and (ii) 3 ensembles of acceptable simulations corresponding to each of the three precipitation-discharge models.

\section{Results and discussion}

\subsection{Point analysis of melt methods}

The calibrated parameter values for the $\mathrm{CD}$ method are $a_{c}=3 \mathrm{~mm} \mathrm{day}^{-1}{ }^{\circ} \mathrm{C}^{-1}, a_{r}=0.8(-)$ and $\theta_{c r}=0.025(-)$. For the TD method, the degree-day and refreezing factors are the same while $\theta_{c r}=0.015(-)$ and the calibrated amplitude factor $\beta$ equals $0.18(-)$. Fig. 6 shows that the $C D$ method cannot capture the strong, diurnal melt variations for either the calibration or validation case. The TD method performs slightly better for the 2007 event and significantly better for the 2008 validation event where most of the peaks are captured. If viewed alongside the temperature time series it is evident that the TD method is the most effective when there is a significant range in the daily maximum and minimum temperatures such as during the 2008 spring event. This result implies that when the temperature differences are greatest, the amplitudes imposed in the TD method are better able to mimic the effect of incoming radiation on snowmelt.

An important point to note for this analysis includes that the temperature drops frequently below zero (unlike the Dranse de Ferret catchment-scale analysis), so it was necessary to have a proper calibration of the refreezing factor $a_{r}$. Overall, the point scale experiment shows that the proposed TD method represents a considerable improvement over the $\mathrm{CD}$ method without using any additional data, only at the cost of one additional calibration parameter.

Furthermore, using the CCEW dataset, a temperature sensitivity analysis was conducted to demonstrate the impact of non-ventilated temperature sensors on the TD and CD methods. Huwald et al. [26] demonstrated a systematic bias with some temperature sensors due to trapping of heat in the temperature shield. The tem- 
2007 Calibration Event

(a)

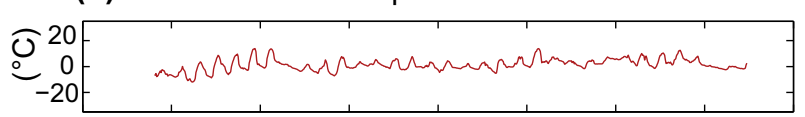

(b)

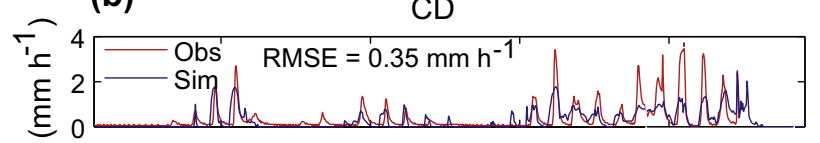

(c)

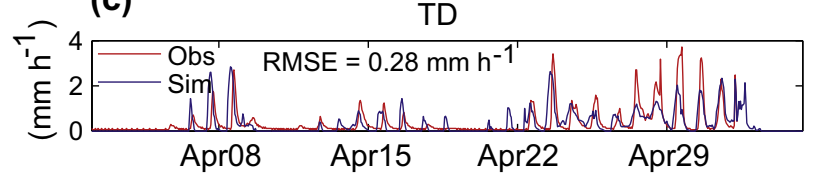

2008 Validation Event

(a)

Temperature

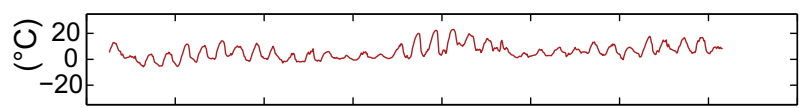

(b)

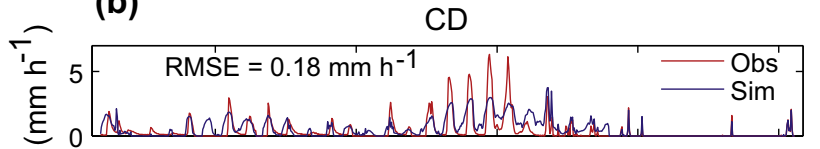

(c)

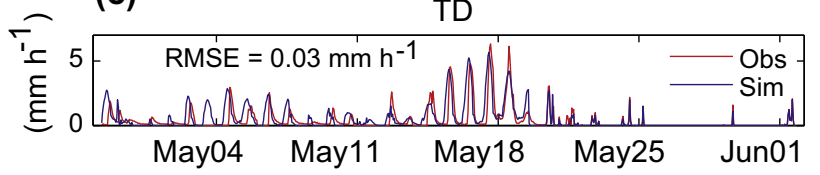

Fig. 6. Point scale analysis (Cotton Creek): (a) temperature time series for the 2007 calibration event (left) and the 2008 validation event (right). Simulated versus measured snowpack outflow for (b) the CD method and (c) the TD method.

perature error is proportional to the incoming shortwave radiation times albedo or the outgoing shortwave radiation. It is inversely proportional to the wind speed. The analysis demonstrated that a $2{ }^{\circ} \mathrm{C}$ bias in maximum daily temperatures on dry days impacts both the $\mathrm{CD}$ and TD methods by overestimating melt rates each time step where the temperature error has a stronger impact on the TD method. It is therefore recommended to use the TD method with ventilated temperature sensors, such as those used with standard meteorological service stations.

\subsection{Distributed point melt analysis}

Potential snowmelt is compared for the three different experiments of temperature distributions (Section 4.2). As previously mentioned, the 'reference' snowmelt is the melt that can be potentially produced with Eq. (2) with measured incoming radiation (instead of potential) at the given stations. In Experiment 1, using temperature observations from all stations, the potential melt for the $C D$, TD and Hock methods are compared with the reference melt series. If the degree-day factors are not calibrated, the Hock method clearly models the reference melt more accurately, as illustrated in Fig. 7a showing the cumulated melt for all methods over the entire simulation period. This shows that overall, the Hock method simulates the potential melt that would be obtained with observed radiation quite well; in other words, the fact that the Hock method uses potential radiation does, for this experiment, not lead to large deviations from the reference.

Subsequently, the degree-day factors of all three methods are calibrated such as to produce exactly the same amount of potential melt as the reference series at the end of the entire observation period (Fig. 7b). The potential melt generated by the calibrated Hock method is still closest to the reference series where the potential melt generated with the CD and the TD methods seems unable to follow the reference series.

This result is due to the length of the observation period, including the very warm conditions in early summer. If only the early part of the observation period, which is effectively relevant for snowmelt, is considered (around 22 days), the CD and TD methods are able to reproduce the reference series as well as the Hock method (see the inset on Fig. 7b). The coefficients of determination ( $R^{2}$ values) of the potential melt generated by the Hock, the TD and the $\mathrm{CD}$ methods versus the reference melt are $0.9,0.9$ and $0.8(-)$ respectively.

The results are similar for Experiments 2 and 3 (Fig. 8) but with one important difference between the methods: for the $\mathrm{CD}$ and the TD method, the calibrated value of $a_{c}$ remains constant throughout all experiments, at $6.9\left(\mathrm{~mm} \mathrm{day}^{-1}{ }^{\circ} \mathrm{C}^{-1}\right)$, whereas for the Hock method, the calibrated degree-day factors are 7, 6.8 and 7.2 for Experiments 1, 2 and 3 respectively. The CD and TD methods are thereby more robust with a consistent degree-day factor for all temperature distributions. Conversely, the Hock method is highly sensitive to the dominant aspect of the meteorological observations since it requires different degree-day factors to reproduce the reference potential melt series from different station groups.

Furthermore, for Experiments 2 and 3, the calibrated CD, TD and Hock methods demonstrate that there is a clear difference in potential melt when either station group is considered (i.e., southeast versus southwest). This result underlines the importance of having good estimates of spatial temperature variability (and namely of lapse rates) to produce good results with degree-day-based melt methods.

The sub-daily variability in simulated melt rates for all three methods is compared in Fig. 9a, which shows for each day of the simulation period and for all methods, the daily mean melt and the maximum and minimum values (for Experiment 1 ). It can be seen that the daily mean values are quite close to the reference series for all three methods. The daily amplitude, however, is strongly underestimated by the $\mathrm{CD}$ method, which confirms the results of the single point analysis. Experiments 2 and 3 show similar results (not shown).

Fig. 9b shows a comparison of the daily minimum and maximum melt for the TD method and the reference potential melt. The diurnal, time-varying degree day factor of the TD method provides an improved means to capture the daily minimum and maximum values of the reference melt. Most significantly, this figure as well as the inset in Fig. 7b showing cumulated melt over the 22day measured melt period, demonstrate that imposing this variability causes the TD method to have a better fit to the reference melt in terms of diurnal pattern. RMSE (root mean square error) values are reduced by moving from the $\mathrm{CD}$ method to the TD method; the error for the daily maximum melt over the time series relative to the reference melt is reduced from 2.2 to $0.7 \mathrm{~mm} \mathrm{~h}^{-1}$. Similarly, the RMSE for the minimum melt is reduced from 6.8 to $0.9 \mathrm{~mm} \mathrm{~h}^{-1}$.

\subsection{Catchment-scale analysis}

\subsubsection{Preliminary path probability analysis}

To illustrate the effect of the source area delineation within the hydrological model, probabilities of flow paths from selected source areas generated by the reference simulation (see 
(a)

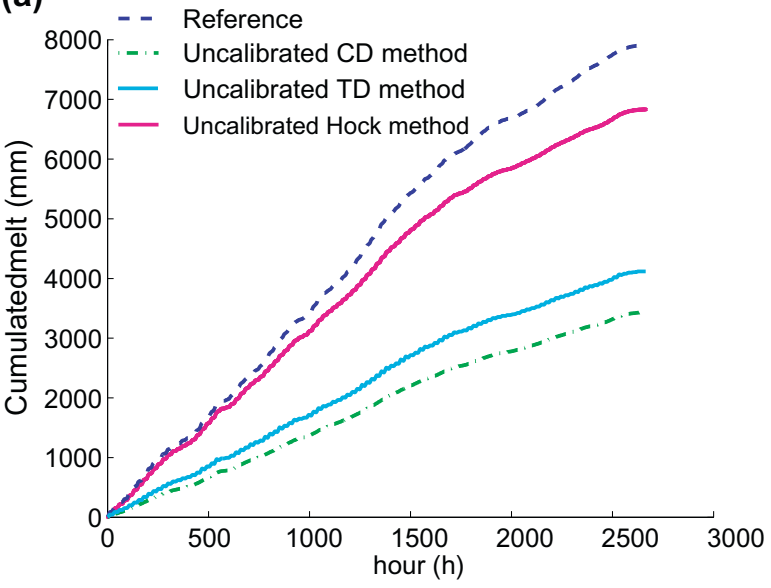

(b)

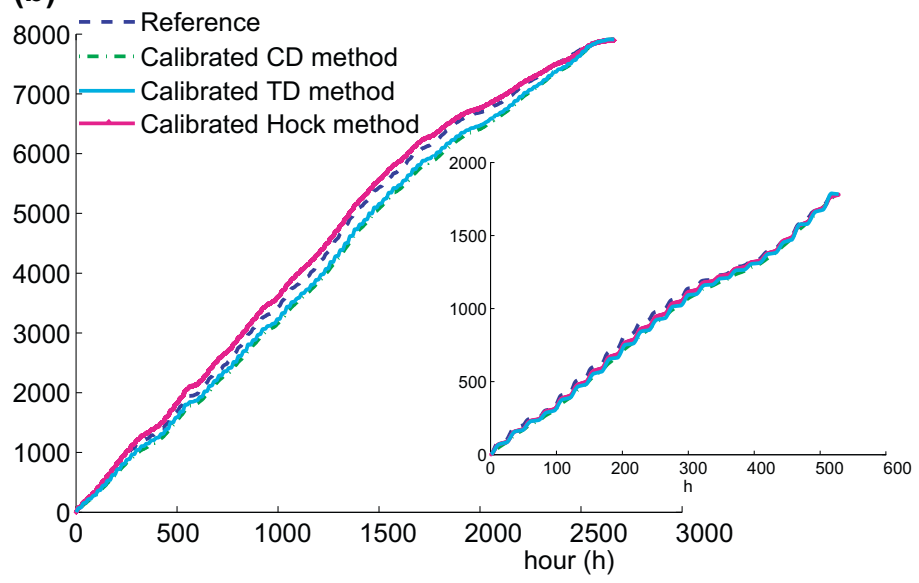

Fig. 7. Distributed point analysis: (a) The reference potential cumulated melt, the melt calculated by the uncalibrated CD, TD and Hock methods. (b) Calibration of the CD, TD and Hock methods in terms of matching the reference potential melt series (cumulated over the entire observation period, 111 days). The inset shows the same result for calibration over the first 22 days.

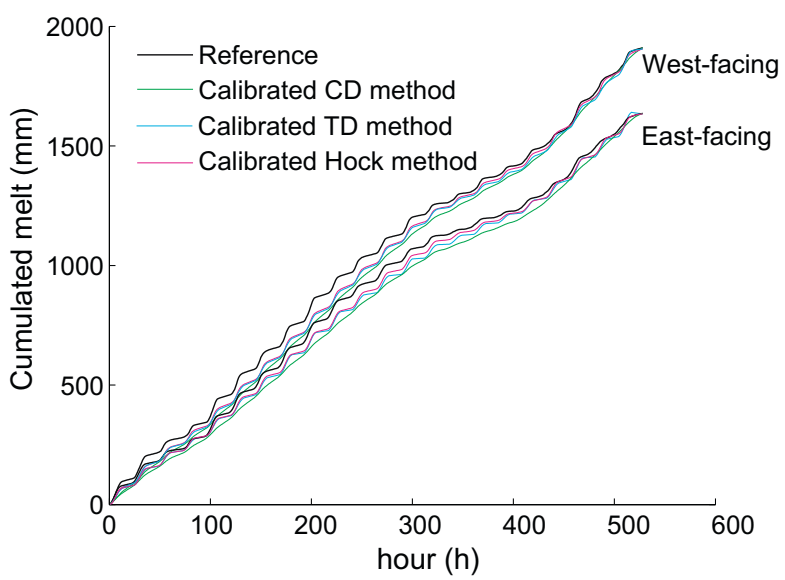

Fig. 8. Distributed point analysis: potential melt for either the southeast or southwest facing group simulated with the three methods and the reference series, cumulated over the first 22 days of the observation period.

Section 4.4) were analyzed. Fig. 10 depicts four examples of source areas with contrasting mean slopes, areas, elevations and aspects and their corresponding 'path probability', i.e. the probability that this source area is activated (through snowpack outflow and rainfall) as a function of time. It can be seen that the path probability is influenced by the area, elevation, slope and aspect of the source area. Intuitively, the greater the source area is in size (Figs. 10a and 10c), the longer this area has an impact on the equivalent precipitation (snowpack outflow and rainfall). Source areas at higher altitudes (Fig. 10c) have a higher path probability later in the melt period, i.e. they have a higher probability to be activated later in the season, which simply results from the deeper snowpack at higher elevations. Similarly, melt from north-facing areas (Figs. 10b) is activated later than melt in south-facing areas (Figs. 10d) due to less frequent exposure to incoming radiation.

\subsubsection{Comparison of the melt methods}

For the catchment-scale analysis, each of the three melt methods is used to generate the equivalent precipitation used in the hydrological model with either all meteorological stations (Experiment 1) or either the southeast or southwest facing groups as input data (Experiments 2 and 3 respectively). Hereafter, we first present an analysis of the spatial results, followed by an analysis of the discharge time series.

The differences in spatial melt are analyzed for the melt methods using a uniform snowpack input for visualization purposes for Experiment 1, after calibrating all parameters according to the method described in Section 4.4. Fig. 11 shows all methods' distribution of snow heights after $200 \mathrm{~h}$ of simulation and the snow height remaining after $200 \mathrm{~h}$ as produced by the measured radiation (the reference melt series). It can be seen that, spatially, the CD and TD methods better capture the reference melt. The Hock method predicts more extreme melt rates throughout the catchment, which can be explained by this model's proven sensitivity to temperature extremes [49] which is evident on a pixel basis.

As already demonstrated in all previous analyses, the CD method cannot be calibrated such as to capture the sub-daily melt amplitudes of the reference discharge. The catchment-scale analysis confirms these results as depicted in Fig. 12a where the CD simulated discharge times series appears to be smoother than the reference discharge (red solid line) and its plausibility range (light red shaded region). In contrast, with the calibrated TD method as well as the calibrated Hock method, the reference series is very well captured (Fig. 12b and c).

Overall, both the TD and Hock methods perform comparably well even if local differences are visible (e.g. the Hock method performs less well for the late rise of discharge but in exchange it captures better earlier peaks). However, in absolute terms, the TD method shows better Nash-Sutcliffe indices with respect to the reference discharge and a greater percentage of discharge simulations which fall into the range of plausible reference simulations (see performance indicators in Fig. 12). It is important to note that the size of the Dranse de Ferret catchment is critical to note the strong diurnal fluctuations visible in Fig. 3. If a larger catchment had been studied, this variability would most likely have been smoothed out.

Moreover, it should be recognized that the reference discharge series might be biased towards one or the other of the studied methods. On one hand, the reference series lends itself to be similar to the TD method discharge because both methods consider the actual, physical conditions, and incoming radiation and temperature have a close relationship as noted by Ohmura [48]. The TD method is also more coherent with the well-known physical relations between minimum and maximum temperature, radiation and melt [72]. On the other hand, the method proposed by Hock is used to distribute the measured radiation across the catchment and in effect, the reference discharge can also be seen to be biased 

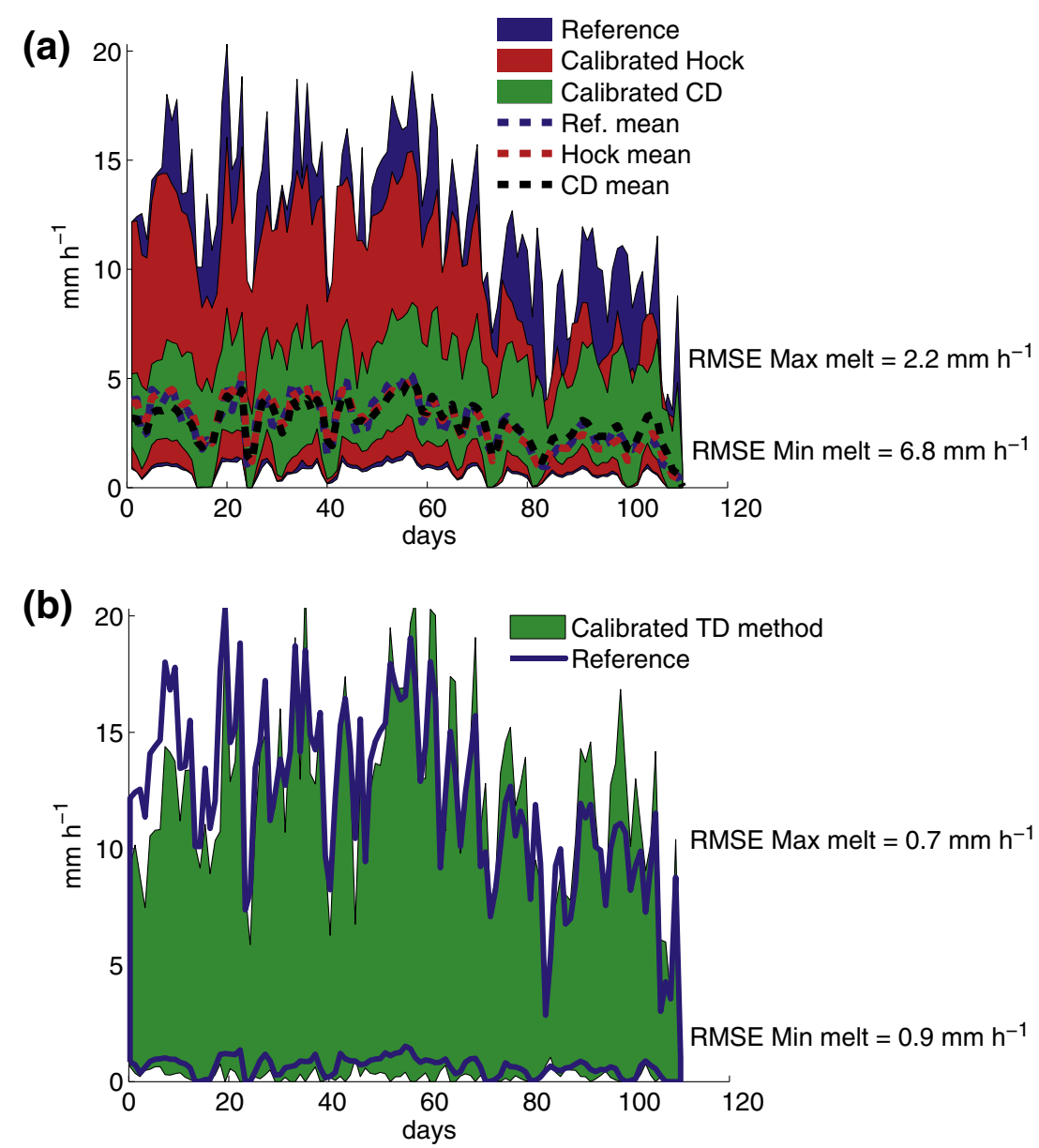

Fig. 9. Distributed point analysis: (a) Potential daily melt variability for the reference melt, the calibrated CD method and the calibrated Hock method. RMSE values compare the minimum and maximum daily melt between the CD and reference cases. Daily mean melt is indicated by the dashed lines. (b) Ranges of daily minimum and maximum melt for the reference melt (blue line) and the calibrated TD method melt (shown in green). RMSE values compare the daily minimum and maximum melt between the TD and reference cases. (For interpretation of the references to colour in this figure legend, the reader is referred to the web version of this article.)

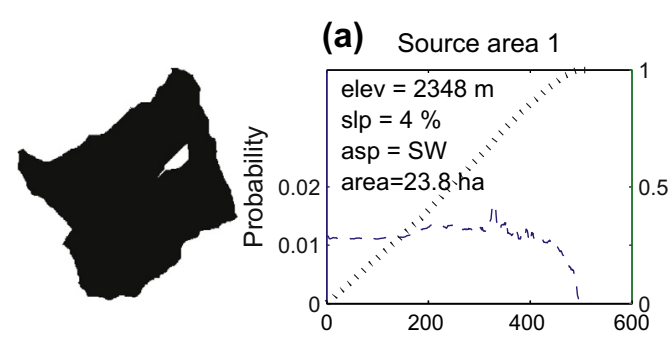

(c) Source area 3

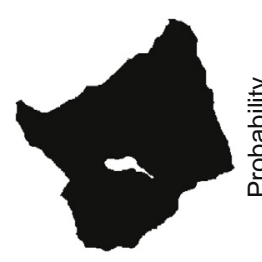

(b) Source area 2

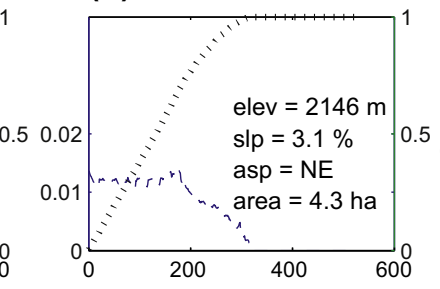

(d) Source area 4
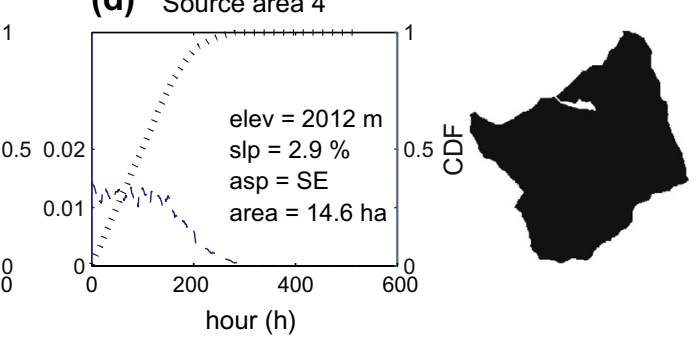

Legend

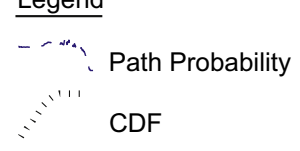

Fig. 10. Time changing path probabilities, (i.e., the probability that the source area is activated through snowpack outflow and rainfall as a function of time) for specific source areas for the melt period considered. The locations of these source areas; their mean elevation (elev), slope (slp), area and aspect (asp) are given as insets. The cumulated distribution function is shown on the right $y$-axis. 

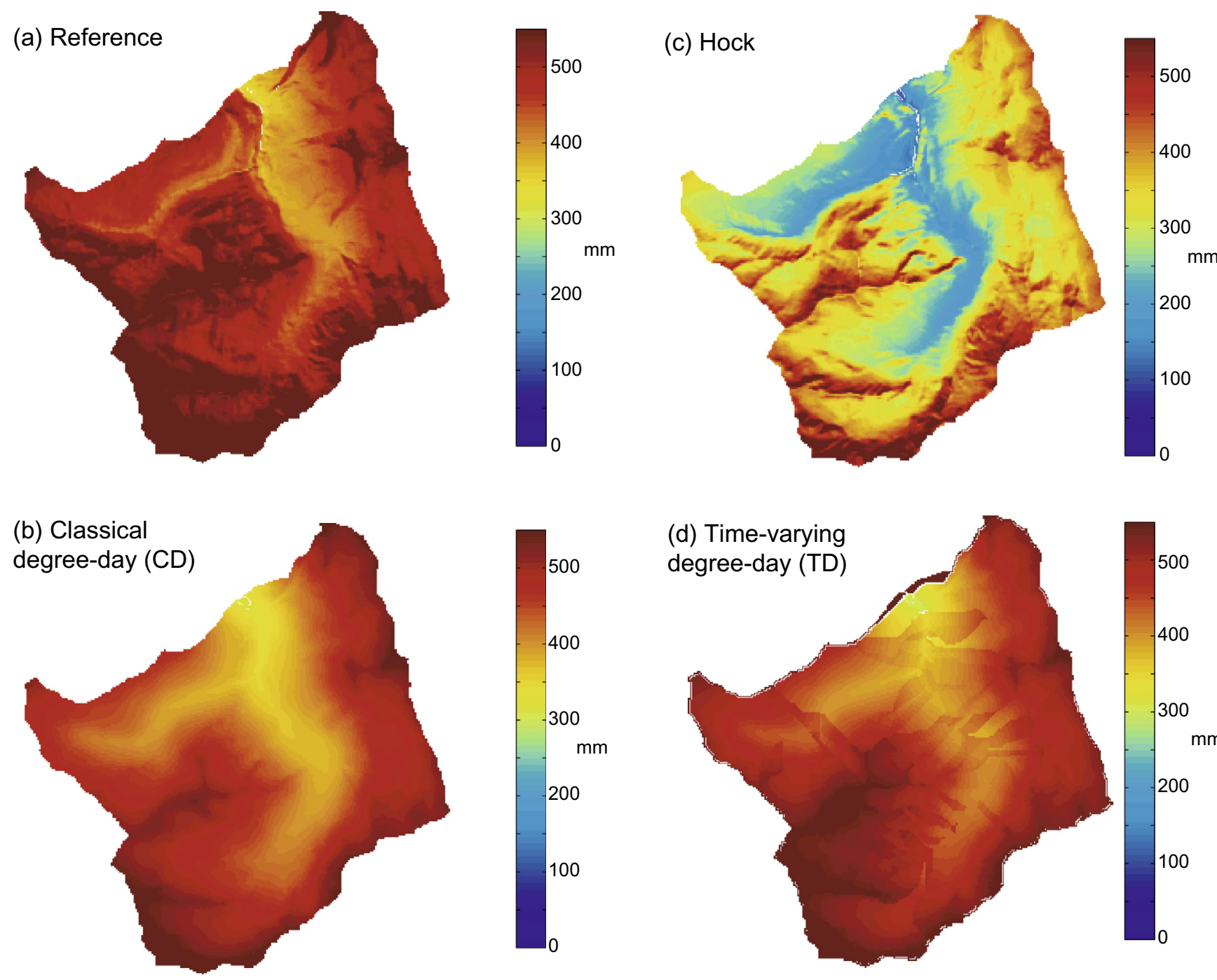

Fig. 11. Distributed point analysis: distribution of snow heights $(\mathrm{mm})$ from a uniform snowpack initialization after $200 \mathrm{~h}$ of simulation for: (a) the reference melt case, (b) the calibrated CD method, (c) the calibrated Hock method and (d) the calibrated TD method.

towards the Hock method in the distributed case. In spite of the possible biases towards the reference case, the comparison of the calibrated TD and Hock method for Experiment 1 leads to the conclusion that considering all temperature observations, both methods perform equally well.

Clear differences between the two methods become visible in Experiments 2 and 3 (Fig. 13). If the temperature distribution data come from only the southwesterly facing group, the discharges are initially higher for the Hock method. A distribution of high mean temperatures attributed to the shallower lapse rates seems to be biasing the Hock melt method. Consequently, the Hock method provides an over-estimation of melt in the main peak hours (hours 75-250) and an underestimation in the lower peak (hours 450525 ) without being able to capture the variability in the recession part of the discharge curve.

In contrast, for Experiment 3, the east-facing case, the results for both methods are comparable qualitatively even if the Hock method outperforms the TD method in terms of having a greater percentage of simulations which fall into the range of plausible reference simulations and the Nash index (see performance indicators in Fig. 13). It is interesting to note that the reference discharge generated by using only the east-facing stations as input contrasts significantly from the reference discharge for the case of using all ten stations. Such a contrasting behavior indicates that the steep, mean lapse rate for the group of east-facing stations generates more variable mean temperatures and makes the discharge behavior quite different. In conclusion, results from Experiments 2 and 3 confirm the sensitivity of both melt methods to the spatial distribution of temperature, but the TD method appears, once again, to be more robust.

In terms of applicability of these melt methods, we would like to recognize that the Hock method has the major advantage that high resolution digital terrain models are now almost universally available; we believe, however, that there are some open questions with regard to the performance of this method as a function of available temperature observations. Regarding the performance of the proposed TD method, it obviously depends on the quality of spatially distributed estimates of daily minimum and maximum temperature, which can, of course, be difficult to obtain even if minimum and maximum temperature observations are quite wide-spread (e.g. in the United States where maximum and minimum thermometers have been installed due to their low cost and reliability [52]). Accordingly, both methods have their specific utility for different types of applications.

Finally, we would like to emphasize that the sub-daily degreeday factor variability could also be obtained by directly relating the daytime degree-day factor to the daytime hourly temperature and by imposing a constant mean value during nighttime. Such an 

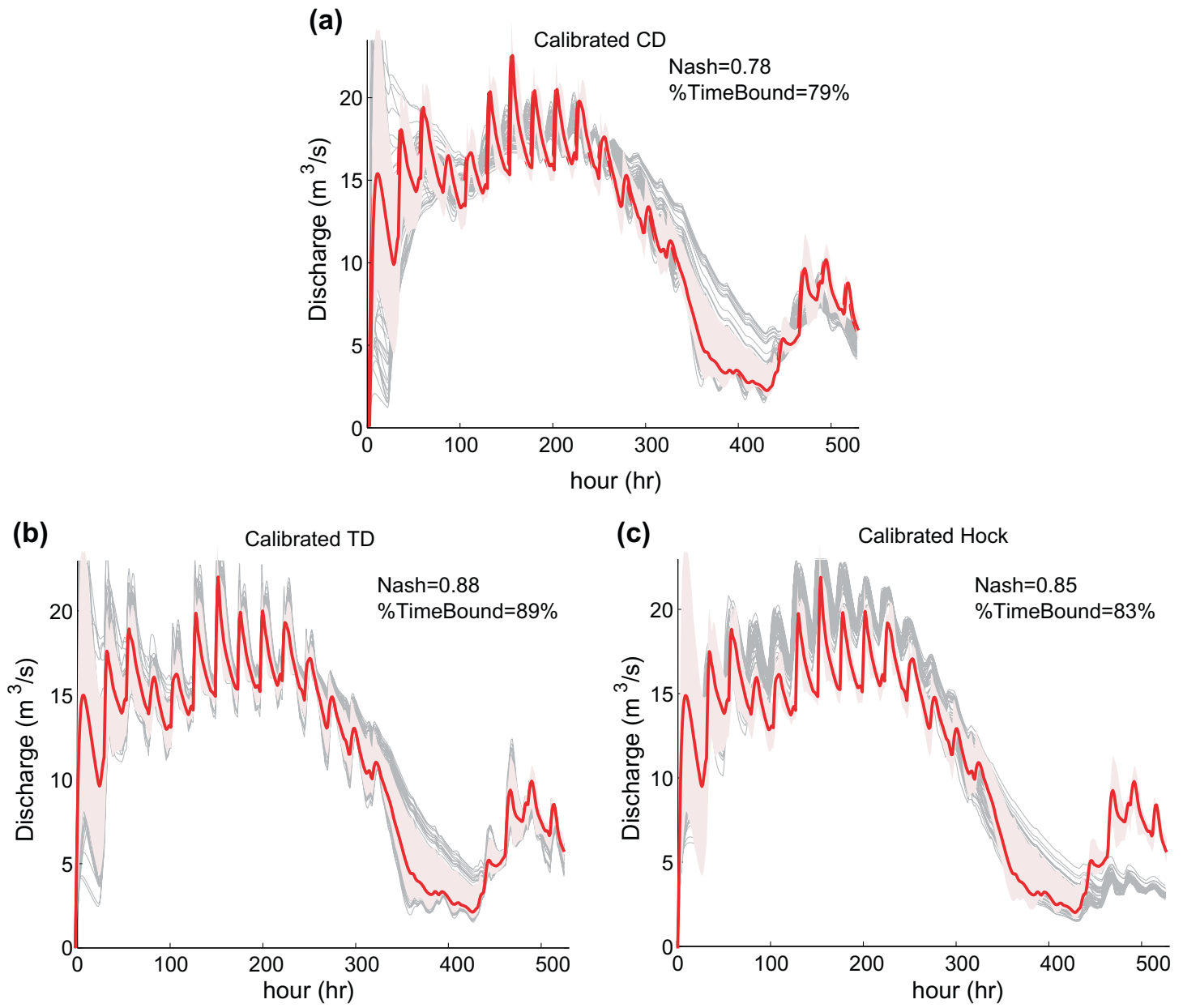

Fig. 12. Catchment scale analysis: The reference (dark red line) with plausibility range (light rose) and simulated discharges (grey) for case study 1 (all 10 stations) for (a) the calibrated CD method, (b) the calibrated TD method and (c) the calibrated Hock method. Discharge time series that have a Nash-Sutcliffe index $\geqslant 0.7$ and $\geqslant 80 \%$ of time steps which fall into the range of plausible reference simulations (except for a) are shown. Best parameter sets gave the following Nash-Sutcliffe indices and percentage of time steps respectively: (a) $0.78,79 \%$, (b) $0.88,89 \%$ and (c) $0.85,83 \%$. (For interpretation of the references to colour in this figure legend, the reader is referred to the web version of this article.)

approach would present two main differences with the proposed TD method: the resulting degree-day factor would have significantly less smooth sub-daily variability and its daily mean would fluctuate. Overall, this might result in too strong a variability of the simulated melt. Additionally, if this methodology is applied to hydrological models already using the classical degree-day approach, replacing the calibrated (constant) degree-day factor with a factor having a fluctuating daily mean value might lead to unforeseen effects on the model performance. As the goal of the proposed method is to impose physically-based variability around calibrated degree-day factors, the development and performance assessment of such a direct-temperature approach is left for future research.

\section{Conclusions}

This paper presents a new extension of the classical degree-day method to simulate hourly snowmelt at the catchment-scale with a time-variable degree-day factor. The proposed quasi-sinusoidal function for the sub-daily variation of the degree-day factor requires only observed daily minimum and maximum temperatures as input, which are widely available. The main findings of the presented model performance comparisons are summarized hereafter:
- The point analysis at the Cotton Creek Experimental Watershed (CCEW) (Canada) demonstrates that the proposed quasi-sinusoidal function for the degree-day factor captures the sub-daily melt variability significantly better than a constant degree-day factor as in the classical degree-day (CD) method.

- The distributed point analyses at the Dranse de Ferret experimental catchment (Switzerland) indicate that, at the point scale, the proposed time-variable (TD) method and the Hock method have relatively equal performances in terms of generating potential melt, i.e. both methods capture the temporal distribution of available melt energy in a very similar way. The performance of the potential radiation-based Hock method demonstrates that this method clearly adds variability. However, the corresponding variability imposed by the TD method is more physically-based and appears to be less sensitive to temperature distributions. These results suggest that additional analyses with distributed meteorological observations can help to further understand how well the snowmelt methods perform as a function of aspect.

- Furthermore, the point data analyses underline that degree-day snowmelt models, which strongly rely on temperature information, require a good representation of the spatial variability of temperature (realistic lapse rates) to correctly model the spatial variability of snowmelt. 
(a)
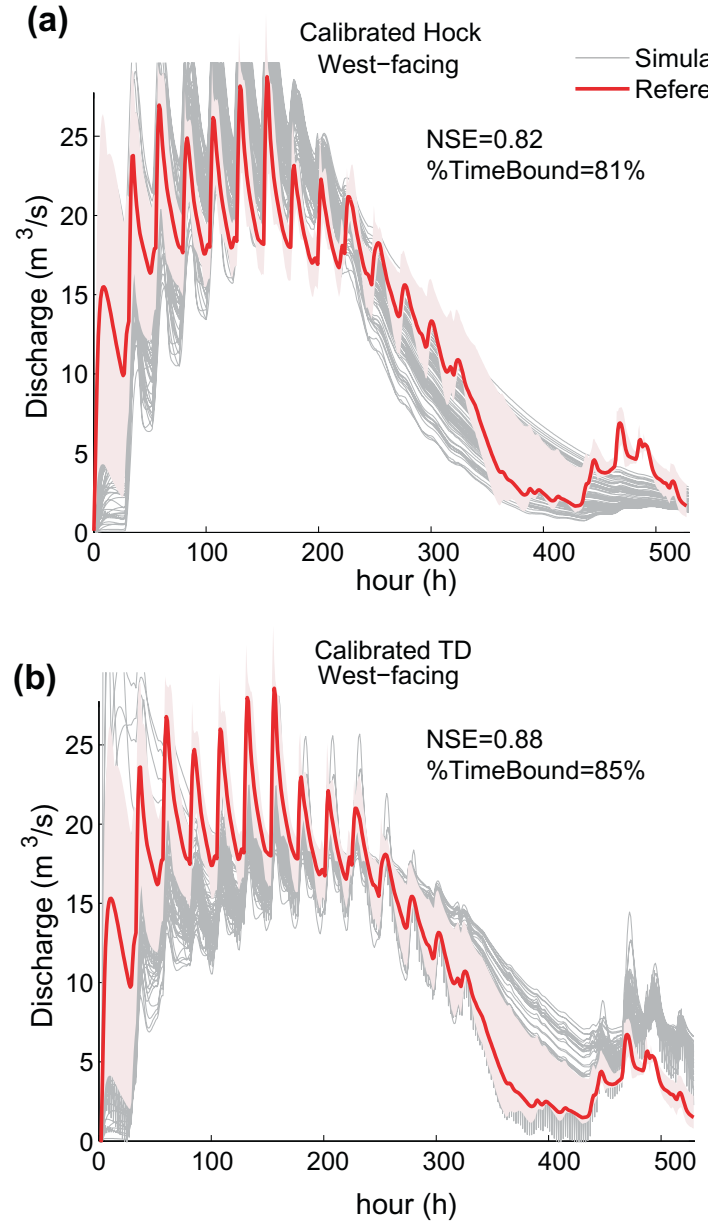

(c)
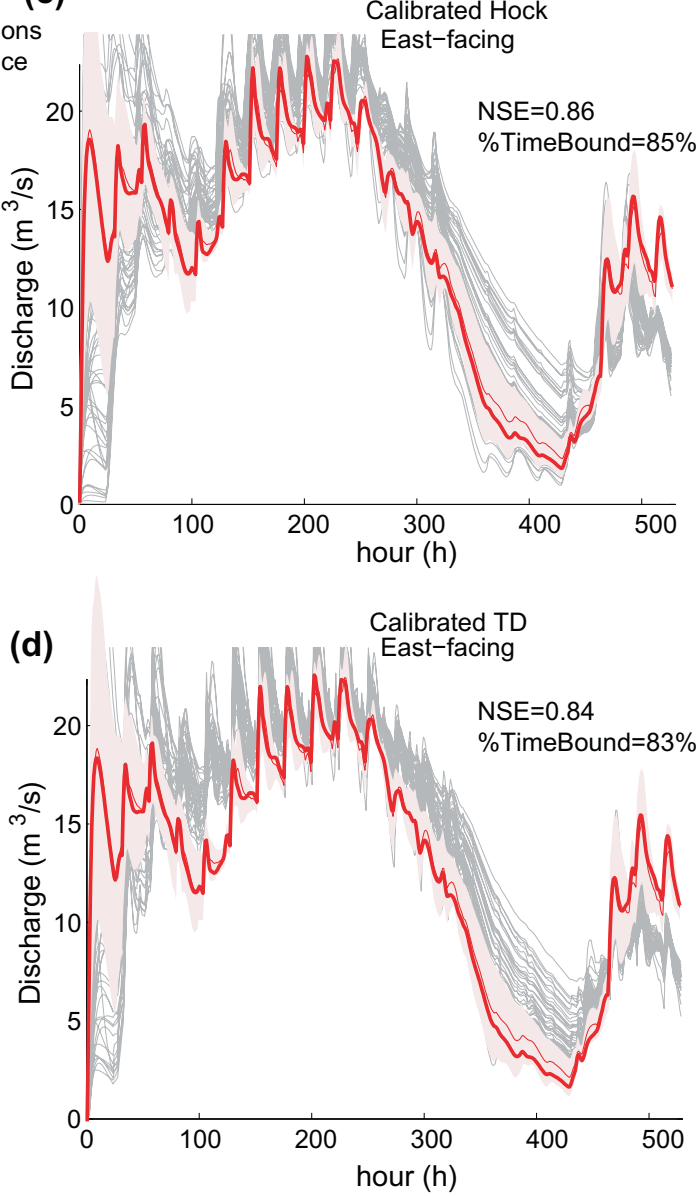

Fig. 13. Catchment scale analysis: the reference (dark red line) with plausibility range (light rose) and simulated discharges (gray) for case studies 2 and 3 ( 5 stations in either group): (a) the calibrated Hock method for west-facing stations, (b) the calibrated TD method for west-facing stations, (c) the calibrated Hock method for east-facing stations and (d) the calibrated TD method for east-facing stations. Simulated discharge time series that have a Nash-Sutcliffe index $\geqslant 0.7$ and $\geqslant 80 \%$ of time steps which fall into the range of plausible reference simulations are shown. Best parameter sets gave the following Nash-Sutcliffe indices and percentage of time steps respectively: (a) $0.82,81 \%$, (b) $0.88,85 \%$, (c) $0.86,85 \%$, and (d) $0.84,83 \%$. (For interpretation of the references to colour in this figure legend, the reader is referred to the web version of this article.)

- In terms of catchment-scale discharge simulation, the presented results for the Dranse de Ferret catchment suggest that the TD method might outperform the potential radiation-based Hock method in terms of spatial variability of hourly snowmelt. Given that the TD method assigns degree-day factors directly at the subcatchment scale rather than at the grid-scale (Hock method), the TD method has, in particular, the advantage of maintaining realistic diurnal melt variations at the scale of an entire hydrological system, which smoothes out, to some degree, small scale variabilities.

Overall, the TD method, based solely on daily maximum and minimum temperature data, proves to be a robust, minimalist approach to provide a suitably accurate snowmelt response for spatially-explicit hydrological models with different degrees of spatial lumping. It, thus, represents a valuable approach for a wide range of hydrological modeling applications in high mountainous environments which are limited in data and require sub-daily snowmelt computations. Further testing of the TD method on the catchment-scale is recommended with distributed temperature datasets, ideally extending over several, seasonal melt periods, to investigate the method's sensitivity to the quality of spatial temperature estimates and to compare this approach with other methods relating sub-daily degree-day factor variability directly to temperature.

\section{Acknowledgements}

The authors thank the EFLUM field campaign team for their collection of the data and the sponsor project, the Swiss Experiment of CCES (www.swiss-experiment.ch). We also thank the Sensorscope Sarl's support in data management for this campaign and Russell Smith and his experimental team at the CCEW for their point scale analysis dataset. We further thank the reviewers, Michi Lehning and Maxmilliano Zappa for their useful suggestions on improving this manuscript. We would like to acknowledge funding by: the MINERVE 2008-2011 project (MR0287, 00.0022.PZ/H124-3960); the Swiss National Science Foundation (SNF), Grant 200021_124930/1); and the ERC Advanced Grant RINEC 22761. The digital elevation data as well as other topographic data were provided by SwissTopo.

\section{References}

[1] Anderson E. National weather service river forecast system-snow accumulation and ablation model. Technical memorandum NWS HYDRO-17. NOAA. US Department of Commerce, Silver Spring, MD; 1973. 217pp.

[2] Bavay M, Lehning M, Jonas T, Lowe H. Simulations of future snow cover and discharge in alpine headwater catchments. Hydrol Process 2009;23:95-108.

[3] Bergström S. Development of a snow routine for the HBV-2 model. Nord Hydrol 1975;6:73-92.

[4] Blöschl G. The influence of uncertainty in air temperature and albedo on snowmelt. Nordic Hydrol 1991;22:95-108. 
[5] Blöschl G, Kirnbauer R. An analysis of snow cover patterns in a small alpine catchment. Hydrol Process 1992;6:99-109.

[6] Bocchiola D, Mihalcea C, Diolaiuti G, Mosconi B, Smiraglia C, Rosso R. Flow prediction in high altitude ungauged catchments: a case study in the Italian Alps (Pantano Basin, Adamello Group). Adv Water Resour 2010;33:1224-34.

[7] Botter G, Bertuzzo E, Rinaldo A. Transport in the hydrologic response: travel time distributions, soil moisture dynamics and the old water paradox. Water Resour Res 2010;46:W03514

[8] Botter G, Rinaldo A. Scale effect of geomorphologic and kinematic dispersion. Water Resour Res 2003;39:1286.

[9] Braun L, Brun E, Durand Y, Martin E, Tourasse P. Simulation of discharge using different methods of meteorological data distribution, basin discretization and snow modelling. Nord Hydrol 1994;25:129-44.

[10] Brubaker K, Rango A, Kustas W. Incorporating radiation inputs into the snowmelt runoff model. Hydrol Process 1996;10:1329-43.

[11] Carenzo M, Pellicciotti F, Rimkus S, Burlando P. Assessing the transferability and robustness of an enhanced temperature-index glacier-melt model. J Glaciol 2009;55:258-74.

[12] Cazorzi F, DallaFontana G. Snowmelt modelling by combining air temperature and a distributed radiation index. J Hydrol 1996;181:169-87.

[13] Debele B, Srinivasan R, Gosain A. Comparison of process-based and temperature-index snowmelt modeling in SWAT. Water Resour Manag 2010;24:1065-88.

[14] Dunn S, Colohan R. Developing the snow component of a distributed hydrological model: a step-wise approach based on multi-objective analysis. J Hydrol 1999;223:1-16.

[15] Goovaerts P. Geostatistics for natural resources evaluation. New York: Oxford University Press; 1997.

[16] Goovaerts P. Using elevation to aid the geostatistical mapping of rainfall erosivity. CATENA 1999;34:227-42.

[17] Gruenewald T, Lehning M. Altitudinal dependency of snow amounts in two small alpine catchments: can catchment-wide snow amounts be estimated via single snow or precipitation stations? Ann Glaciol 2011;52:153-8.

[18] Gupta V, Waymire E, Wang E. A representation of the instantaneous unit hydrograph from geomorphology. Water Resour Res 1980;16:855-62.

[19] Hamlin L, Pietroniro A, Prowse T, Soulis R, Kouwen N. Application of indexed snowmelt algorithms in a northern wetland regime. Hydrol Process 1998; $12: 1641-57$

[20] Hebeler F, Purves R. The influence of resolution and topographic uncertainty on melt modelling using hypsometric sub-grid parameterization. Hydrol Process 2008;22:3965-79.

[21] Herrmann A, Rau R. Snow cover stores and winter runoff behavior of a small basin in the german highlands. In: Snow Hydrologic Research in Central Europe: Proc. Hann. Munden Meeting, DVWK-Mitteilungen 7 Bonn; 1984. p. 449-72.

[22] Hingray B, Schaefli B, Mezghani A, Hamdi Y. Signature-based model calibration for hydrological prediction in mesoscale alpine catchments. Hydrol Sci J 2010;55:1002-16.

[23] Hock R. A distributed temperature-index ice- and snowmelt model including potential direct solar radiation. J Glaciol 1999;45:101-11.

[24] Hock R. Temperature index melt modelling in mountain areas. J Hydrol 2003;282:104-15

[25] Huss M, Farinotti D, Bauder A, Funk M. Modelling runoff from highly glacierized alpine drainage basins in a changing climate. Hydrol Process - Sp Iss 2008;22:3888-902

[26] Huwald H, Higgins C, Boldi MO, Bou-Zeid E, Lehning M, Parlange M. Albedo effect on radiative errors in air temperature measurements. Water Resour Res 2009;45:W08431.

[27] Ingelrest F, Barrenetxea G, Schaefer G, Vetterli M, Couach O, Parlange M. Sensorscope: application-specific sensor network for environmental monitoring. ACM Trans Sensor Networks 2010;6.

[28] Jost G, Moore RD, Smith R, Gluns D. Distributed temperature-index snowmelt modelling for forested catchments. J Hydrol 2012;420-421:87-101.

[29] Jost G, Weiler M, Gluns D, Alila Y. The influence of forest and topography on snow accumulation and melt at the watershed-scale. J Hydrol 2007;347:101-15.

[30] Kling H, Furst J, Nachtnebel H. Seasonal, spatially distributed modelling of accumulation and melting of snow for computing runoff in a long-term largebasin water balance model. Hydrol Process 2006;20:2141-56.

[31] Kling H, Gupta H. On the development of regionalization relationships for lumped watershed models: The impact of ignoring sub-basin scale variability. J Hydrol 2009;373:337-51.

[32] Klok E, Jasper K, Roelofsma K, Gurtz J, Badoux A. Distributed hydrological modelling of a heavily glaciated alpine river basin. Hydrol Sci J 2001;46: 553-70.

[33] Kobierska F, Jonas T, Magnusson J, Zappa M, Bavay M, Bosshard T, Paul F, Bernasconi S. Climate change effects on snowmelt and discharge of a partly glacierized watershed in central switzerland (SoilTrec Critical Zone Observatory). Appl Geochem 2011;26:S60-2.

[34] Koboltschnig G, Schoner W, Holzman H, Zappa M. Glaciermelt of a small basin contributing to runoff under the extreme climate conditions in the summer of 2003. Hydrol Process 2009;23:1010-8.

[35] Konz M, Uhlenbrook S, Braun L, Shrestha A, Demuth S. Implementation of a process-based catchment model in a poorly gauged, highly glacerized himalayan headwater. Hydrol Earth Syst Sci 2007;11:1323-39.

[36] Kustas W, Rango A, Uijlenhoet R. A simple energy budget algorithm for the snowmelt runoff model. Water Resour Res 1994:30:1515-27.
[37] Kuusisto E. On the values and variability of degree-day melting factor in Finland. Nord Hydrol 1980;34:235-42.

[38] Laio F, Porporato A, Ridolfi L, Rodriguez-Iturbe I. Plants in water-controlled ecosystems: active role in hydrologic processes and response to water stress: II. Probabilistic soil moisture dynamics. Adv Water Resour 2001;24:707-23.

[39] Lehning M, Gruenewald T, Schirmer M. Mountain snow distribution governed by an altitudinal gradient and terrain roughness. Geophys Res Lett 2011;38.

[40] Lehning M, Volksch I, Gustafsson D, Nguyen T, Stahli M, Zappa M. ALPINE3D: a detailed model of mountain surface processes and its application to snow hydrology. Hydrol Process 2006;20:2111-28.

[41] Li X, Williams M. Snowmelt runoff modelling in an arid mountain watershed, Tarim Basin, China. Hydrol Process 2008;22:3931-40.

[42] Magnusson J, Farinotti D, Jonas T, Bavay M. Quantitative evaluation of different hydrological modelling approaches in a partly glacierized swiss watershed. Hydrol Process 2011;25:2071-84.

[43] Maidment D. Handbook of hydrology. New York: McGraw-Hill; 1993

[44] Nadeau D, Brutsaert W, Parlange M, Bou-Zeid E, Barrenetxea G, Couach O, Boldi MO, Selker J, Vetterli M. Estimation of urban sensible heat flux using a dense wireless network of observations. Environ Fluid Mech 2009;9:635-53.

[45] Nash J, Sutcliffe J. River flow forecasting through conceptual models, Part I - A: Discussion of principles. J Hydrol 1970;3:282-90.

[46] Nicótina L, Celegon EA, Rinaldo A, Marani M. On the impact of rainfall patterns on the hydrologic response. Water Resour Res 2008;44:W12401.

[47] Nicótina L, Schaefli B, Tarboton D, Rinaldo A. Model coupling instead of calibration: what can a catchment model learn from landscape evolution? In: EGU (Ed.), Geophys. Res. Abstracts, EGU General, Assembly; 2011. p. EGU201110099.

[48] Ohmura A. Physical basis for the temperature-based melt-index method. J Appl Meteorol 2001;40:753-61.

[49] Pellicciotti F, Brock B, Strasser U, Burlando P, Funk M, Corripio J. An enhanced temperature-index glacier melt model including the shortwave radiation balance: development and testing for haut glacier d'arolla, Switzerland. J Glaciol 2005;51:573-87.

[50] Pomeroy J, Toth B, Granger R, Hedstrom N, Essery R. Variation in surface energetics during snowmelt in a subarctic mountain catchment. J Hydrometeorol 2003;4:702-19.

[51] Priestley C, Taylor R. On the assessment of surface heat flux and evaporation using large scale parameters. Mon Weather Rev 1972;100:81-92.

[52] Quayle R, Easterling D, Karl T, Hughes P. Effects of recent thermoment changes in the cooperative station network. B Am Meteorol Soc 1991;72:1718-23.

[53] Rango A, Martinec J. Revisting the degree-day method for snowmelt computations. Water Resour Bull 1995;31:657-69.

[54] Rinaldo A, Botter G, Bertuzzo E, Settin T, Uccelli A, Marani M. Transport at basin-scales, 1. Theoretical framework. Hydrol Earth Syst Sci 2006;10:19-26.

[55] Rinaldo A, Rigon R, Marani A. Geomorphological dispersion. Water Resour Res $1991 ; 28: 513-25$.

[56] Rodriguez-Iturbe I, Porporato A. Ecohydrology of water-controlled ecosystems. Cambridge University Press; 2004.

[57] Rodriguez-Iturbe I, Porporato A, Laio F, Ridolfi L. Plants in water-controlled ecosystems: active role in hydrologic processes and response to water stress: I. Scope and general outline. Adv Water Resour 2001;24:695-705.

[58] Rodriguez-Iturbe I, Rinaldo A. Fractal river basins: chance and selforganization. Cambridge University Press; 1997.

[59] Rodriguez-Iturbe I, Valdés J. The geomorphologic structure of hydrologic response. Water Resour Res 1979;15:1409-20.

[60] Rohrer M, Braun L. Long-term records of snow cover water equivalent in the swiss alps 2. Simulation. Nord Hydrol 1994;25:65-78.

[61] Rossa A, Liechti K, Zappa M, Bruen M, Germann U, Hasse G, Keil C, Krahe P. The cost 731 action: a review on uncertainty propagation in advanced hydrometeorological forecast systems. Atmos Res 2010;100:150-67.

[62] Schaefli B, Hingray B, Musy A. Climate change and hydropower production in the swiss alps: quantification of potential impacts and related modelling uncertainties. Hydrol Earth Syst Sci 2007;11:1191-205.

[63] Schaefli B, Hingray B, Niggli M, Musy A. A conceptual glacio-hydrological model for high mountainous catchments. Hydrol Earth Syst Sci 2005;9:95-109.

[64] Simoni S, Padoan S, Nadeau D, Diebold M, Porporato A, Barrenetxea G, et al. Hydrologic response of an alpine watershed: application of a meteorological wireless sensor network. Water Resour Res 2011;47.

[65] Slater A, Bohn T, McCreight J, Serreze MC, Lettenmaier D. A multimodel simulation of pan-arctic hydrology. J Geophys Res Biogeosci 2007;112:1-17.

[66] Smith, R. Space-time dynamics of runoff generation in a snowmelt-dominated montane catchment. $\mathrm{PhD}$ thesis. Univ British Columbia, Vancouver. Department of Geography; 2011.

[67] Stahl K, Moore R, Floyer J, Asplin M, McKendry I. Comparison of approaches for spatial interpolation of daily air temperature in a large region with complex topography and highly variable station density. Agr Forest Meteorol 2006;139:224-36.

[68] Tarboton D. A new method for the determination of flow directions and upslope areas in grid digital elevation models. Water Resour Res 1997;33:309-20.

[69] Tobin C, Nicótina L, Parlange M, Berne A, Rinaldo A. Improved interpolation of meteorological forcings for hydrologic applications in a Swiss Alpine region. J Hydrol 2011;401:77-89.

[70] Tobin C, Rinaldo A, Schaefli B. Snowfall limit forecasts and hydrological modeling. J Hydrometeorol 2012;13:1507-19. 
[71] Viviroli D, Zappa M, Gurtz J, Weingartner R. An introduction to the hydrological modelling system PREVAH and its pre- and post-processing tools. Environ Modell Softw 2009;24:1209-22.

[72] Walter M, Brooks E, McCool D, King L, Molnau M, Boll J. Process-based snowmelt modeling: does it require more input data than temperature-index modeling? J Hydrol 2005;300:65-75.
[73] Woods R. Analytical model of seasonal climate impacts on snow hydrology: Continuous snowpacks. Adv Water Resour 2009;32:1465-81.

[74] Zappa M, Pos F, Strasser U, Warmerdam P, Gurtz J. Seasonal water balance of an Alpine catchment as evaluated by different methods for spatially distributed snowmelt modelling. Nord Hydrol 2003;34:179-202. 